\title{
Interface Science Using Ambient Pressure Hard X-ray Photoelectron Spectroscopy
}

\author{
Marco Favaro ${ }^{1, *} \mathbb{C}$, Fatwa Firdaus Abdi ${ }^{1}$, Ethan Jon Crumlin ${ }^{2}$, Zhi Liu ${ }^{2,3}$, Roel van de Krol ${ }^{1}$ \\ and David Edward Starr 1 ,* \\ 1 Helmholtz-Zentrum Berlin für Materialien und Energie GmbH, Institute for Solar Fuels, \\ Hahn-Meitner-Platz 1, D-14109 Berlin, Germany; fatwa.abdi@helmholtz-berlin.de (F.F.A.); \\ roel.vandekrol@helmholtz-berlin.de (R.v.d.K.) \\ 2 Advanced Light Source, Lawrence Berkeley National Laboratory, 1 Cyclotron Rd, Berkeley, CA 94720, USA; \\ ejcrumlin@lbl.gov (E.J.C.); liuzhi@shanghaitech.edu.cn (Z.L.) \\ 3 School of Physical Science and Technology, ShanghaiTech University, Pudong, Shanghai 201210, China \\ * Correspondence: marco.favaro@helmholtz-berlin.de (M.F.); david.starr@helmholtz-berlin.de (D.E.S.); \\ Tel.: +49-(0)30-8062-42835 (M.F.); +49-(0)30-8062-42320 (D.E.S.)
}

Received: 18 December 2018; Accepted: 24 January 2019; Published: 28 January 2019

\begin{abstract}
The development of novel in situ/operando spectroscopic tools has provided the opportunity for a molecular level understanding of solid/liquid interfaces. Ambient pressure photoelectron spectroscopy using hard X-rays is an excellent interface characterization tool, due to its ability to interrogate simultaneously the chemical composition and built-in electrical potentials, in situ. In this work, we briefly describe the "dip and pull" method, which is currently used as a way to investigate in situ solid/liquid interfaces. By simulating photoelectron intensities from a functionalized $\mathrm{TiO}_{2}$ surface buried by a nanometric-thin layer of water, we obtain the optimal photon energy range that provides the greatest sensitivity to the interface. We also study the evolution of the functionalized $\mathrm{TiO}_{2}$ surface chemical composition and correlated band-bending with a change in the electrolyte $\mathrm{pH}$ from 7 to 14 . Our results provide general information about the optimal experimental conditions for characterizing the solid/liquid interface using the "dip and pull" method, and the unique possibilities offered by this technique.
\end{abstract}

Keywords: in situ ambient pressure XPS; hard X rays; photoelectron simulations; solid/liquid interface; $\mathrm{TiO}_{2}$; $\mathrm{APTES}$

\section{Introduction}

Molecular-level processes occurring at solid/liquid interfaces are intriguing not only from a fundamental physical-chemical perspective, but also from a practical perspective since they are an essential part of (photo)electrochemical systems, which are key to future renewable energy storage technologies. This provides a powerful driving force for the development of novel in situ/operando characterization tools that can directly probe the interface [1-7]. For a complete understanding of the solid/liquid interface, it is mandatory to investigate the properties of the solid bulk, the bulk liquid, and the thin interface layer between the solid and the liquid phases [8]. This constitutes the most important part of the solid/liquid junction where specific adsorption of ions, charge transfer dynamics and electrical potential formation occur.

On the other hand, the measurement of the interface layer properties is a challenging task. First, it requires operando or in situ experimental capabilities in order to capture the true makeup of the interfacial layer under operating or realistic working conditions, respectively $[1,8,9]$. Secondly, to characterize the true interfacial properties, one should use an experimental probe that limits the 
perturbation of the junction itself. Therefore, several spectroscopic methods based on photon in/photon out or photon in/electron out approaches have been applied to investigate solid/liquid interfaces. Among them, synchrotron-based techniques such as surface X-ray diffraction, X-ray absorption/emission and photoelectron spectroscopy, and "laboratory-based" techniques, such as infrared, Raman and non-linear optical spectroscopies have been recently developed [10].

In this context, X-ray photoelectron spectroscopy (XPS) stands as an excellent characterization tool, since it offers elemental and chemical sensitivity, simultaneously measuring local built-in electrical potentials via the detection of rigid photoelectron kinetic energy shifts in both core and valence levels [11-17]. Due to the high vapor pressure of many liquids of interest, differential pumping schemes have to be used in photoelectron analyzers to minimize the elastic and inelastic scattering of electrons in the gas phase above the liquid side of the junction [18-20]. In addition, small sample-to-analyzer aperture working distances (WDs) must be used, for the same purpose [18-20]. A reasonable trade-off needs to be found between limiting the electron scattering by the gas phase molecules and keeping the pressure at the sample surface above $90-95 \%$ of the nominal pressure in the chamber. Usual WDs (at which the analyzer focus is optimized) are about the diameter of the aperture itself [18-20]. Modern state-of-the-art electron analyzers are capable to operate at pressures of and above $30 \mathrm{mbar}$ (the vapor tension of water at room temperature) and at high photoelectron kinetic energies (KEs, up to $12 \mathrm{keV}$ ) [11]. The extension of AP-XPS to high photon energies (i.e., high photoelectron KEs) has two main advantages: the reduced photoelectrons/gas molecules scattering provides higher signal intensity at higher gas pressure (i), whereas the high photoelectron KEs lead to increased photoelectron inelastic mean free paths (IMFPs) in the liquid (ii). The latter enables the investigation of solid/liquid junctions through liquid layers with thickness on the same order of the IMFP (ii).

Two additional challenges exist for the AP-XPS investigation of solid/liquid electrolyte interfaces. The first is the preparation of stable liquid films thick enough to be representative of a realistic solid/liquid interface, but thin enough to allow photoelectrons ejected from the interfacial region to penetrate and emerge from the liquid on their path to the photoelectron analyzer. The second is the tuning of the experimental conditions (detection geometry, photon energy etc.) to enhance the photoelectron signal coming from the interface.

In this work, we briefly describe the so-called "dip and pull" method that can be used as a way to investigate the solid/liquid interface in situ by coupling it with ambient pressure hard X-ray photoelectron spectroscopy (AP-HAXPES) using X-ray energies between 2.0 and $10.0 \mathrm{keV}$ [21].

By using a model system of a solid/liquid interface and numerical simulations, we estimate the optimal photon energy range for the signal coming from the interface. The simulations have been generated using the Simulation of Electron Spectra for Surface Analysis (SESSA) software [22]. Our model system is a $\mathrm{TiO}_{2}$ surface functionalized with 1 monolayer equivalent (1 MLE) of 3-aminopropyl triethoxysilane (APTES). Alkylsilanes adsorb at the surface of transition metal oxides [23] as self-limiting monolayer systems, thereby constituting ideal interfaces. Furthermore, APTES contains one nitrogen and silicon atom, whose corresponding 1s photoionization yield was monitored as a function of the photon energy. The difference in binding energy (BE) between these two core levels (N 1s BE $\sim 400 \mathrm{eV}$, Si 1s BE $1850 \mathrm{eV}$ ) will be used to highlight the different photoionization yield trends with the photon energy.

In the last part of this work, we report on the evolution of the APTES-functionalized $\mathrm{TiO}_{2}$ surface chemistry and correlated band-bending by systematically changing the $\mathrm{pH}$ of the aqueous electrolyte from 7 to 14. This was performed at beamline 9.3.1 at the Advanced Light Source (ALS, Lawrence Berkeley National Laboratory, Berkeley, U.S.A.) [11]. Our results provide general information about the experimental conditions that allow for an optimal characterization of the solid/liquid interface using the "dip and pull" method and AP-HAXPES, showing at the same time the capabilities offered by this technique to address fundamental questions in energy materials and conversion research. 


\section{Materials and Methods}

\subsection{Numerical Simulation Details}

The simulations reported in this work have been generated using the Simulation of Electron Spectra for Surface Analysis (SESSA) software (National Institute of Standards and Technology, Gaithersburg, MD, USA.) [22].

The APTES thickness corresponding to 1 monolayer equivalent (MLE) was found as follows, using SESSA simulations. First, $1 \mathrm{ML}$ of $\mathrm{TiO}_{2}$ having a thickness of $3.57 \AA$ (the relaxed Ti-Ti distance along the rutile (110) direction [24]) was supported on a planar $\mathrm{Cu}$ substrate. Then, the APTES layer thickness deposited atop the $\mathrm{TiO}_{2}$ film was systematically varied until the differential cross section-normalized integrated photoelectron intensities of Ti $2 \mathrm{p}$ and $\mathrm{Si} 1 \mathrm{~s}$ were identical. This leads to an identical concentration of $\mathrm{Si}$ atoms with respect to the Ti atoms contained within $1 \mathrm{ML}$ of $\mathrm{TiO}_{2}$ (for practical reasons chosen along the rutile (110) direction). Therefore, the thickness of APTES corresponding to $1 \mathrm{MLE}$ on rutile $\mathrm{TiO}_{2}(110)$ was found to be $12.7 \AA$.

Note that the differential cross sections $(\mathrm{d} \sigma / \mathrm{d} \Omega)_{n l}$ (the probability for photoelectrons to be emitted into the solid angle $\mathrm{d} \Omega$ ) were computed in SESSA using the first order nondipole approximation, in which nondipole effects are treated in a perturbative manner. Within the Cooper parametrization, the differential cross section $(\mathrm{d} \sigma / \mathrm{d} \Omega)_{n l}$ for $100 \%$ linearly polarized radiation [25] can be expressed as follows:

$$
(\mathrm{d} \sigma / \mathrm{d} \Omega)_{n l}=\left(\sigma_{n l} / 4 \pi\right) \times\left\{\left[1+\frac{1}{2} \beta_{n l} \times\left(3 \cos ^{2} \alpha-1\right)\right]+\left[\sin \alpha \cos \varphi \times\left(\delta+\gamma \cdot \cos ^{2} \alpha\right)\right]\right\}
$$

$\sigma_{n l}$ is the total photoionization cross section (TPCS) for a core level described by a principal and angular quantum number $n$ and $l, \beta_{n l}$ is the corresponding asymmetry parameter describing the anisotropy of the photoelectron angular distribution, $\alpha$ is the angle formed between the photoelectron direction $k$ and the polarization vector $\varepsilon, \varphi$ is the angle formed between the radiation Poynting vector $S$ (parallel to the propagation direction) and the plane containing $k$ and $\varepsilon$ (see Figure 1 for the definition of the aforementioned angles). Since the simulations have been performed considering radiation from a synchrotron (horizontal photon beam) and bending magnet as source (electric field polarization vector laying on the orbit plane, see Figure 1), the angle $\varphi$ is equal to $0^{\circ}$ for all $\alpha$ values (in our simulations, $\alpha=15^{\circ}$ as implemented at BL 9.3.1, ALS). The term within the first square parentheses represents the dipole contribution, whereas the second term is the parametrization of the first order nondipole effects, which are non-negligible for photon energies above $2000 \mathrm{eV}$ [25]. Within the nonrelativistic single-electron approximation, the $\gamma$ parameter represents the major correction term corresponding to electric dipole-quadrupole interference. The magnetic dipole term, $\delta$, can only be present if core-relaxation occurs [25]. $\delta$ and $\gamma$, as well as $\sigma_{n l}$ and $\beta_{n l}$, are explicit functions of the photon energy. Finally, the take-off angle $\theta$ (angle between the photoelectron direction $\boldsymbol{k}$ and the normal $\boldsymbol{n}$ to the sample surface) was kept to $0^{\circ}$ for all the simulations (normal emission detection, NE).

The atomic density (number of emitters per unit volume) of $\mathrm{TiO}_{2}$ and APTES used in the simulations were equal to $9.568 \times 10^{22} \mathrm{~cm}^{-3}$ and $9.522 \times 10^{22} \mathrm{~cm}^{-3}$, respectively (the APTES stoichiometry used in the simulations was $\mathrm{SiNO}_{3} \mathrm{C}_{9} \mathrm{H}_{23}$ ). The energy gap between the valence and conduction bands of $\mathrm{TiO}_{2}$ was set to $3.03 \mathrm{eV}$ [26]. The energy gap between the HOMO and LUMO of APTES was determined from the fluorescence spectrum of APTES, which exhibits an intense band at about $438 \mathrm{~nm}$ [27]. The related HOMO-LUMO energy gap was therefore estimated to be equal to $2.83 \mathrm{eV}$.

To complete the model of the solid/liquid interface, a liquid water layer with a thickness of $20 \mathrm{~nm}$ was placed atop the sample surface, as schematically reported in Figure 1. This value has been taken as a realistic representation of the liquid layer thickness typically obtained during "dip and pull" experiments. The water atomic density and band gap used in the SESSA simulations were $1.003 \times 10^{23} \mathrm{~cm}^{-3}$ and $6.9 \mathrm{eV}[28]$, respectively. 


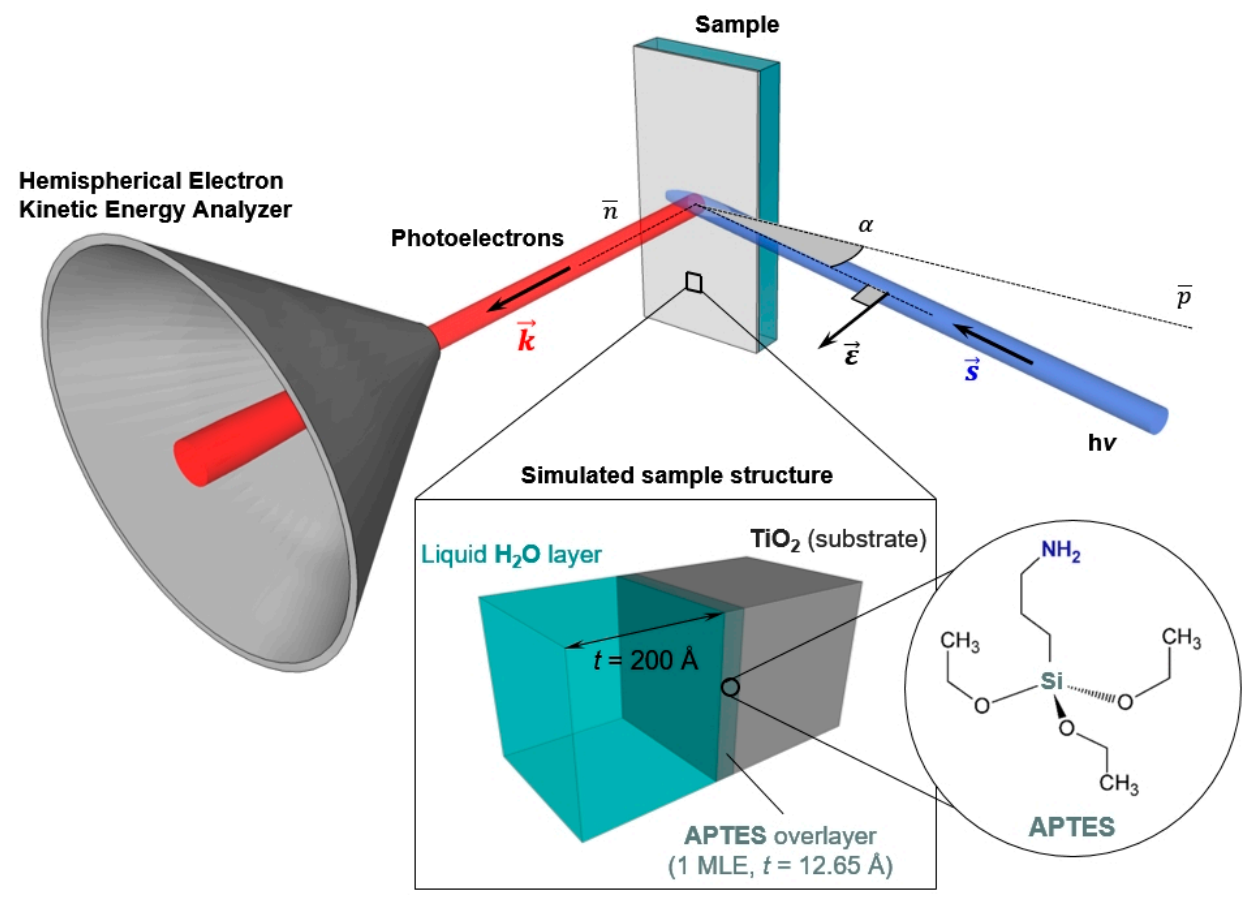

Figure 1. Schematization of the ambient pressure hard X-ray photoelectron spectroscopy (AP-HAXPES) experimental geometry (implemented in Simulation of Electron Spectra for Surface Analysis (SESSA) calculations) and 3-aminopropyl triethoxysilane (APTES)-functionalized $\mathrm{TiO}_{2}$ model system used in this work.

\subsection{Sample Preparation}

The $\mathrm{TiO}_{2}$ precursor solution was made by mixing titanium-isopropoxide (Alfa-Aesar, Haverhill, MA, USA.) with glacial acetic acid (Sigma-Aldrich, Saint Louis, MO, USA.) in anhydrous ethanol. $1 \mathrm{~mL}$ of Ti-isopropoxide was added to $5 \mathrm{~mL}$ of anhydrous ethanol followed by adding varying amounts of glacial acetic under vigorous stirring to give mole ratios ranging from 1:1 to 1:2, Ti-isopropoxide:acetic acid. All solutions resulted in $\mathrm{TiO}_{2}$ films of similar quality. The precursor solution was spin-coated onto FTO/glass substrates in four $100 \mu \mathrm{L}$ aliquots at $2000 \mathrm{rpm}$ for $120 \mathrm{~s}$. Prior to spin coating the substrates were sonicated in a 1\% solution of Triton X-100 (Sigma-Aldrich, Saint Louis, MO, USA.) in de-ionized water, DI water, and a 1:1 solution of acetone:absolute ethanol, followed by a final sonication in DI water. The spin-coated films were sintered at $500{ }^{\circ} \mathrm{C}$ for $12 \mathrm{~h}$.

The $\mathrm{TiO}_{2}$ coated substrates were functionalized with APTES by placing the dried $\left(300{ }^{\circ} \mathrm{C}\right.$ for $15 \mathrm{~min}$ ) substrates into a solution of $0.25 \mathrm{~mL}$ APTES in $100 \mathrm{~mL}$ of anhydrous toluene under $\operatorname{Ar}(\mathrm{g})$ at $80{ }^{\circ} \mathrm{C}$ for $5 \mathrm{~h}$. Following reaction, the APTES $/ \mathrm{TiO}_{2}$ coated substrates were dried at $70{ }^{\circ} \mathrm{C}$ for $30 \mathrm{~min}$ and packed into vacuum sealed bags in a $\mathrm{N}_{2}(\mathrm{~g})$ filled glove box.

\subsection{In Situ AP-HAXPES Measurements and Beamline 9.3.1 Experimental Details}

The source for beamline 9.3.1 at the Advanced Light Source (ALS) of Lawrence Berkeley National Laboratory is a bending magnet. A Si(111) double crystal monochromator (DCM) provides an energy range between 2000 and $6000 \mathrm{eV}$ (denoted as "hard" throughout the text to be consistent with the acronym HAXPES). The minimum X-ray spot size on the sample is $0.7 \mathrm{~mm}(\mathrm{v}) \times 1.0 \mathrm{~mm}(\mathrm{~h})$. All spectra were taken with a photon energy of $4000 \mathrm{eV}$, at room temperature, and in NE (see Figure 1 for a schematic of the experimental geometry). The pressure in the experimental chamber was kept at the equilibrium vapor pressure of the aqueous electrolyte solution at room temperature. To limit evaporation from the electrochemical cell a large volume $(\sim 500 \mathrm{~mL})$ of outgassed pure water was introduced in the analysis chamber. 
The pass energy of the Scienta analyzer (R4000 HiPP-2, Scienta, Uppsala, Sweden) was set to $200 \mathrm{eV}$. A step size of $100 \mathrm{meV}$ and a dwell time of $300 \mathrm{~ms}$ was used. Under these conditions, the total resolution (X-ray and electron analyzer) was equal to about $550 \mathrm{meV}$ at $4.0 \mathrm{keV}$, determined by measuring the spectral broadening of a gold Fermi edge taken on a clean polycrystalline surface. Binding energy (BE) scale calibration was done by using the $\mathrm{Au} 4 \mathrm{f}_{7 / 2}(\mathrm{BE}=84.00 \mathrm{eV})$ photoelectron peak position taken on a clean gold polycrystalline surface as reference values measured under all the experimental conditions. During operation, the sample and the electron energy analyzer were commonly grounded. Spectral fitting was carried out using a Doniach-Sŭnjić shape for the Au $4 \mathrm{f}$ photoelectron peaks, whereas symmetric pseudo-Voigt functions (G/L ratio ranging from 85/15 to $75 / 25$ ) were used to fit the $\mathrm{Si} 1 \mathrm{~s}$, $\mathrm{O} 1 \mathrm{~s}, \mathrm{Ti} 2 \mathrm{p}$ and N 1 s core levels (after Shirley background subtraction). During the fitting procedure, the Shirley background was optimized together with the spectral components. Finally, chi-square $\left(\chi^{2}\right)$ minimization was ensured by the use of a nonlinear least-squares routine, with increased stability over simplex minimization.

\section{4. "Dip and Pull" Method and in Situ Measurements}

Prior to its introduction into the experimental chamber, the aqueous solutions at different $\mathrm{pH}$ (see Table 1) were outgassed for at least $30 \mathrm{~min}$ at low pressure (between 10 and 20 Torr) in a dedicated offline chamber. After degassing, the electrolyte solution was placed into the AP-HAXPES analysis chamber, where the pressure was carefully decreased to just below equilibrium vapor pressure of the electrolyte at room temperature (the chamber was pumped by a MVP 035-2 diaphragm pump, Pfeiffer Vacuum, Aßlar, Germany). Then, the pumping via the diaphragm pump was stopped and the pressure drifted up to the equilibrium vapor pressure of the used electrolyte solution at room temperature (Table 1). At this point, the only active pumping was provided by the aperture of the HEA nozzle that separates the high pressure analysis chamber from the differentially-pumped electrostatic lens system (aperture diameter: $300 \mu \mathrm{m}$ ). To create the solid/liquid electrolyte interface, the sample was immersed deeply into the aqueous solution. It was then slowly extracted from the liquid by raising the sample manipulator at a constant rate $\left(100 \mu \mathrm{m} \mathrm{s}^{-1}\right)$. Following this procedure, a thin layer of aqueous electrolyte film was formed on the sample surface. The latter was then positioned at the intersection of the X-ray beam and the focal point of the hemispherical electron analyzer (HEA), thereby allowing AP-HAXPES measurements of the solid/liquid interface.

Table 1. Concentration and $\mathrm{pH}$ values for the different aqueous solutions used in this study. The water vapor partial pressure above pure water and $\mathrm{KOH}$ aqueous solutions at different concentration has been determined using the Bridgeman-Aldrich [29] and the Balej equation [29], respectively.

\begin{tabular}{cccc}
\hline Aqueous Solution & $\begin{array}{c}\text { KOH Concentration } \\
{\left[\mathbf{M =}=\mathbf{m o l ~ L}^{-1}\right]}\end{array}$ & $\mathbf{p H}$ & $\begin{array}{c}\mathbf{H}_{\mathbf{2}} \mathbf{O} \text { Vapor Partial } \\
\text { Pressure at r.t. }(=\mathbf{2 9 8} \mathbf{K}) \\
{[\mathbf{m b a r}]}\end{array}$ \\
\hline $\mathrm{mQ} \mathrm{H}_{2} \mathrm{O}$ & - & 7 & 31.67 \\
$\mathrm{KOH} 0^{-4} \mathrm{M}$ & $10^{-4}$ & 10 & 31.41 \\
$\mathrm{KOH} 10^{-2} \mathrm{M}$ & $10^{-2}$ & 12 & 31.39 \\
$\mathrm{KOH} 1.0 \mathrm{M}$ & 1.0 & 14 & 30.29 \\
\hline
\end{tabular}

\section{Results and Discussion}

\subsection{The Challenge of Preparing a Realistic Solid/Liquid Interface}

The main challenge in the investigation of solid/liquid interfaces using a photon in/electron out technique lies in the preparation of the interface itself. The electron detection implies that the electrons ejected from the interfacial region need to penetrate through condensed phases whose thickness must be less than two to three times the electron inelastic mean free path (IMFP). Although the use of hard X-rays allows obtaining high photoelectron KEs (and therefore IMFPs), a photoelectron having a KE 
spanning from $2000 \mathrm{eV}$ to $10000 \mathrm{eV}$ is characterized by an IMFP on the order of tens of nanometers. This poses severe limitations and constraints in the preparation of the solid/liquid interface.

Currently, two different preparation and investigation approaches are used, which differ from each other for the side of the interface that is used for the X-ray incidence and electron detection [9].

Photoelectron spectroscopy can be conducted from the solid side of the solid/liquid interface using few layer graphene membranes supporting the solid phase $[30,31]$. Although this technique is appealing for the fact that gases or liquids can be flown through the system thereby providing facile mass transport, it limits the investigation to thin solid films since the photo-emitted electrons must travel through the solid phase/graphene membrane to reach the photoelectron analyzer. For instance, a photoelectron travelling in Au with a KE of 500 and $5000 \mathrm{eV}$ is characterized by an IMFP of about 0.8 and $4.2 \mathrm{~nm}$, respectively. Using the definition of the information depth as three times the IMFP (i.e., the depth in the material at which $95 \%$ of the ejected photoelectrons are inelastically scattered in their path toward the surface), we find that the maximum probed thickness of Au achievable with soft (hard) X-rays is equal to about $2 \mathrm{~nm}(13 \mathrm{~nm})$.

A second approach, using $\mathrm{X}$-ray incidence and electron detection from the liquid side, requires the formation of a thin liquid layer atop the solid surface [9]. This approach has the advantage of being able to investigate a broad range of solid materials of arbitrary thickness. This is particularly important for photoelectrochemical (PEC) interfaces, due to the diffusion length of the excited charge carriers $\left(\lambda_{C C}\right)$ that can span from tens to hundreds of $\mathrm{nm}$. This poses a constraint on the thickness $(t)$ of the investigated semiconductor, where $t \sim \lambda_{\mathrm{CC}}$. In addition, such approach is applicable to fundamental investigations at interfaces such as the probing of the electrical potential distribution simultaneously within the solid (i.e., band-bending) and the liquid side of the junction (the double/diffuse layer) [13,17].

Similar to the previous discussion, the maximum thickness of the liquid layer must be three times the photoelectron IMFP to allow the photoelectrons ejected from the interface to penetrate the liquid film, to cross the liquid/gas interface and finally to travel through the gas phase on their path toward the electron analyzer. Therefore, for photoelectrons traveling in water with a $\mathrm{KE}$ of $500 \mathrm{eV}$ and $5000 \mathrm{eV}$, the maximum water thickness must be equal to about $6 \mathrm{~nm}$ and $38 \mathrm{~nm}$, respectively.

The preparation of liquid layers characterized by a thickness of the order of tens of nanometer and that are stable for the duration of the measurements (often several hours) is not straightforward and requires the development of novel techniques. As schematically reported in Figure 2, three experimental procedures have been identified to obtain such "free-surface" liquid layers: the "emersion technique" (recently called "dip and pull", Figure 2a), "the tilted sample" procedure (Figure 2b) and the "offset droplet" method (Figure 2c).

The "dip and pull" method was developed from the early works on the extended liquid meniscus of Bockris and Cahan [32], Siegbahn [33] and in particular by Hansen and Kolb [34-36]. It obtains nanometer-thick liquid layers by partially extracting the sample from the liquid solution under controlled conditions (i.e., equilibrium between the liquid and its vapor at a given temperature, constant rate of pulling). This method will be discussed in detail in the next Section 3.1.1.

In "the tilted sample" technique developed by Kötz and coworkers [37], the liquid is contained in a pocket in which the sample is immersed with a tilt angle. This tilt creates a region at the boundary between the liquid free surface and the sample that can be positioned at the focal point of the analyzer and irradiated by the X-ray beam. The authors were able to detect the photoelectron spectra of the elements of the investigated ionic liquid (1-ethyl-3-methylimidazolium tetrafluoroborate) and of the $\mathrm{Pt}$ sample simultaneously in one survey spectrum, using the $\mathrm{Al} \mathrm{K}_{\alpha}$ emission line as excitation source [37]. Similar to what has been described above, it is possible to create a stable evaporation/condensation equilibrium by dosing water in the analysis chamber to match the water vapor pressure above the liquid contained in the pocket, at the given temperature of the experiment. 


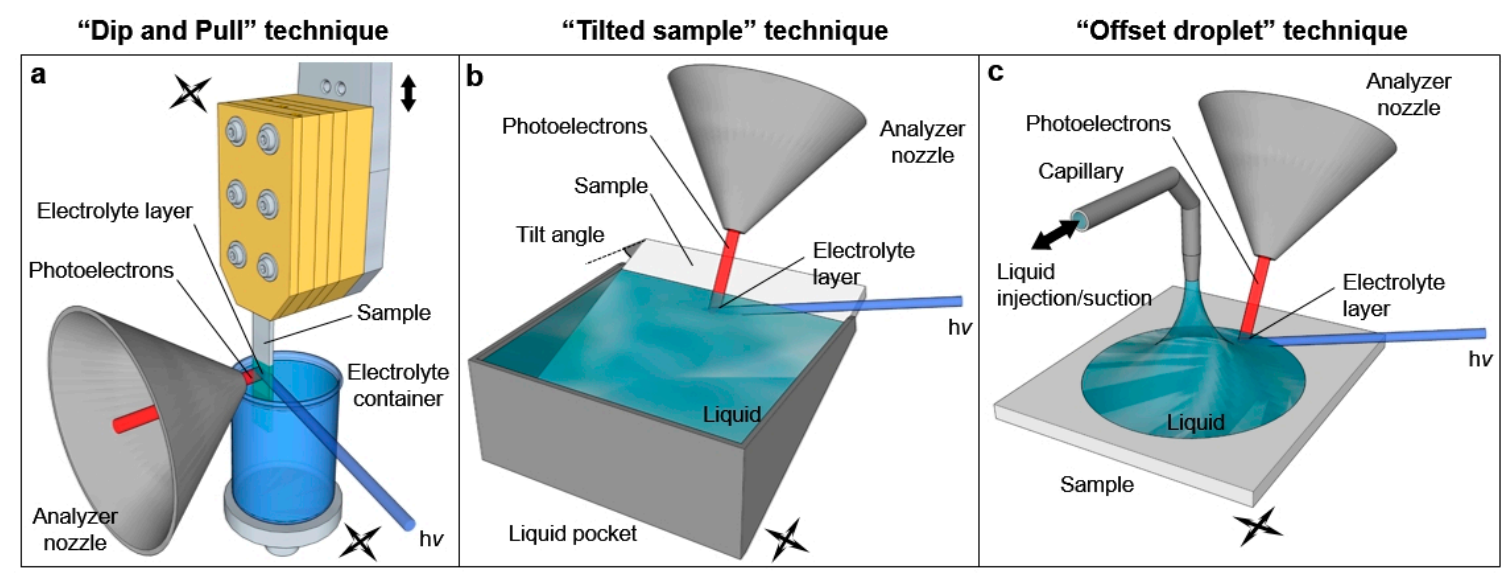

Figure 2. Schematization of the "dip and pull" (a), "tilted sample" (b) and "offset droplet" techniques (c) that are successfully used to prepare free-surface liquid layers thin enough to probe the solid/liquid interface using photoelectron spectroscopy.

Recently, Walton and coworkers developed instead an alternative way by using a fine capillary (100 $\mu \mathrm{m}$ internal diameter) to inject and control a droplet deposited in situ on the sample surface [38]. Since an offset exists between the position of the capillary and the measurement spot, the authors named this technique as the "offset droplet" method. The capillary is connected with an external HPLC pump via a liquid feedthrough. By applying a fixed flow rate to the pump, the liquid can be directly introduced into the analysis chamber and deposited on the sample surface. After an initial transient in which the pressure in the analysis chamber will equilibrate to the liquid vapor tension, a steady-state condition can be reached by choosing an appropriate flow to counterbalance the evaporation rate. By rigidly moving the sample and the capillary, the droplet edge can be positioned at the intersection of the photon beam and the analyzer focus, enabling therefore photoemission experiments at the solid/liquid interface.

It is worth mentioning that the three aforementioned techniques do not allow a fine control of the liquid layer thickness, although it is possible to "select" the suitable thickness for the experimental purposes. With the "dip and pull" technique, it is possible to change the height of the measurement spot by changing the positions of the sample and liquid container with respect to the X-ray beam-analyzer focus intersection. The same procedure can be applied to the "tilted sample" and "offset droplet" techniques, by changing the tilt angle and the liquid injection/suction rate, respectively. The described procedure holds exclusively for wettable surfaces, where the contact angle $\psi$ at the liquid meniscus is smaller than $90^{\circ}$ (indicating relatively intense interactions between the solid and the liquid). This poses a severe restriction on the type of samples/surfaces accessible using these techniques, due to the fact that no nanometric-thick continuous liquid layer can be formed on non-wettable surfaces $\left(\psi \geq 90^{\circ}\right)$. A practical example of this drawback will be given in Section 3.3.

\subsubsection{The "Dip and Pull" Method}

Figure 3 reports a schematization of the "dip and pull" procedure. The sample is first placed in front of the analyzer nozzle, aligning its bottom edge with the nozzle aperture (Figure 3a). The sample is then lowered till its bottom edge enters in contact with the liquid free surface in the electrolyte beaker (Figure $3 b$ ). By measuring these two positions using the sample manipulator encoder, it is possible to get the value $d$, which is the distance between the nozzle aperture and the free surface of the electrolyte (typically some millimeters). The sample is then immersed into the liquid by the same length, plus an additional portion $\Delta$ (Figure 3c). The sample is then retracted from the liquid by a distance $d$, as reported in Figure $3 \mathrm{~d}$. In this manner, the point $P$ that was previously placed at the liquid meniscus (liquid/gas interface) is now aligned with the nozzle aperture, thereby facilitating the search of the optimal liquid layer thickness. By scanning the region around $P$ (changing the height 
of the measurement spot as reported above) it is possible to find the suitable layer thickness for the experiment (in the case of AP-HAXPES the film thickness can span from few to some tens of $\mathrm{nm}$ ).

The liquid film thickness depends on a number of factors and their corresponding interplays: on the wettability of the solid surface for a given liquid (i), the height of the measurement spot above the free surface of the bulk liquid (ii), the presence of an eventual temperature gradient between the two positions (iii), and the solvent evaporation rate (iv). To counterbalance water evaporation from both the liquid layer and the container, two options can be used: either dosing water in the analysis chamber through a valve connected with a heated external reservoir, or by introducing a second (larger) water volume within the analysis chamber. Both solutions work at pressures close to the water vapor pressure at room temperature (100\% relative humidity, $\mathrm{RH})$, thus generating a dynamic equilibrium at the thin liquid layer where the evaporation and condensation rates are the same. Then, by moving the sample (and the liquid container accordingly), the interface can be positioned at the intersection of the incident $\mathrm{X}$-ray beam and the focal point of the electron analyzer, thereby enabling in situ photoemission measurements of the solid/liquid interface.

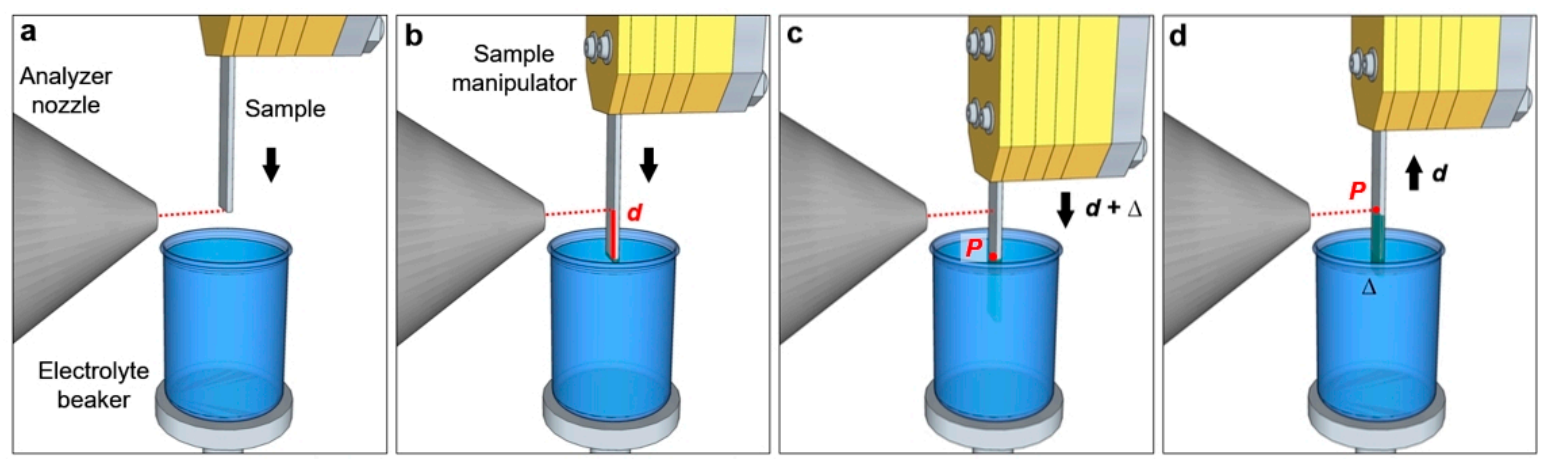

Figure 3. Schematization of the "dip and pull" method coupled with AP-HAXPES experiments. See text for the detailed explanation of the experimental procedure. The pressure inside the analysis chamber is generally close to the water vapor pressure at room temperature, thus enabling to work at about $100 \%$ relative humidity.

The "dip and pull" method can be also utilized to perform in situ (photo)electrochemical and photoemission measurements. Two additional electrodes can be mounted on the sample holder, leading to an effective three-electrode electrochemical cell [11-17]. The bottom part of the electrodes $(\Delta)$, being kept in the bulk electrolyte, provides the electrochemical continuity to apply a potential to the thin electrolyte layer on the sample (working electrode) surface, thus enabling the investigation of solid/liquid electrified interfaces [11-17]. A drawback of this method (and, in general, of the "free-surface" liquid layer approach) is constituted by the mass transport limitation in the electrolyte layer, since the latter is effectively static in the direction parallel to the solid surface (with the exception of liquid flow due to eventual differences in the temperature between the electrolyte reservoir and the measurement spot above the liquid meniscus, causing thermo-capillary or Bénard-Marangoni convection). The mass transport limitations have been experimentally addressed in our recent works $[15,39]$. We have demonstrated that the liquid layer undergoes instability for faradaic reactions involving consumption of the electrolyte, such as during the oxygen evolution reaction (OER) in 1.0 M KOH aqueous solution [39]. Holding the potential at the Pt working electrode at $+1.93 \mathrm{~V}$ vs. RHE (reversible hydrogen electrode), we observed the loss of potential control within the liquid layer in less than $2 \mathrm{~h}$ from the beginning of the experiment [39]. The loss of anodic polarization was assessed by the deviation of the binding energy (BE) shift of the $\mathrm{O}$ 1s liquid phase water (LPW) component and $\mathrm{K} 2 \mathrm{p}$ core levels from the applied OER potential, as a function of the observation time [39]. The following mechanism is likely to occur: first, the hydroxyl anions are depleted from the thin liquid layer due to the ongoing oxidation to molecular oxygen. Second, the consequent decrease over time of the $\mathrm{pH}$ within the liquid layer leads to an increasing IR drop, which is responsible for 
the observed BE deviation from the applied potential. Interestingly, after the loss of potential control occurred, we observed also an important decrease of the LPW signal mirrored by the K $2 p$ intensity, thereby indicating a progressive thinning of the liquid layer. To estimate the diffusion time scale of the hydroxyl groups from the liquid meniscus through the liquid layer, we can use Fick's first law of diffusion (Equation (2)). The distance $z$ of the liquid meniscus from the AP-HAXPES measurement position is typically about $0.8 \mathrm{~mm}$, and the diffusion coefficient $D$ of hydroxyl anions in water at infinite dilution at room temperature is equal to $5.30 \times 10^{-5} \mathrm{~cm}^{2} \mathrm{~s}^{-1}$ [40].

$$
J_{\|}=n /(\Sigma \times \Delta t)=-D(d \mathrm{C} / d \mathrm{z})_{\|}
$$

$J_{\|}$represents the diffusional flux parallel to the sample surface, which is the amount of hydroxyl groups $(n$, in mol) flowing through the liquid layer cross-section $(\Sigma)$ within the time $\Delta t$, whereas $(d \mathrm{C} / d \mathrm{z})_{\|}$is the 1-dimensional concentration gradient within the liquid layer (parallel to the sample surface) between the measurement spot and the liquid meniscus. First, we take into account a liquid layer thickness of $20 \mathrm{~nm}$, which is a typical value for the "dip and pull" technique, and $0.7 \mathrm{~mm}$ as the lateral dimension of the sample. The cross-section $\Sigma$ of the electrolyte film is therefore $0.7 \mathrm{~cm} \times 20 \times 10^{-7} \mathrm{~cm}=1.4 \times 10^{-6} \mathrm{~cm}^{2}$. Secondly, let us define a complete depletion of hydroxyl within the liquid layer after a time $\Delta t$. This sets the concentration gradient $(d \mathrm{C} / d \mathrm{z})_{\|}$to be linear between the measurement spot and liquid meniscus, where the $\mathrm{OH}^{-}$concentration $(\mathrm{C})$ is nominally equal to $1.0 \mathrm{M}\left(1 \mathrm{~mol} \mathrm{~L}^{-1}\right)$. Therefore, $(d \mathrm{C} / d \mathrm{z})_{\|}=1 \mathrm{~mol} \mathrm{~L}^{-1} / 0.8 \mathrm{~cm}=10^{-3} \mathrm{~mol} \mathrm{~cm}^{-3} / 0.8 \mathrm{~cm} \mathrm{=}$ $1.25 \times 10^{-3} \mathrm{~mol} \mathrm{~cm}^{-4}$. We can then determine the flux $J$ of hydroxyl through the cross section $\Sigma$ per unit time: $J_{\|}=n /(\Sigma \times \Delta t)=\mathrm{C} \times \Sigma \times z / \Sigma \times \Delta t=\mathrm{C} \times z / \Delta t=10^{-3} \mathrm{~mol} \mathrm{~cm}{ }^{-3} \times 0.8 \mathrm{~cm} / \Delta t=$ $8.0 \times 10^{-4} \mathrm{~mol} \mathrm{~cm}{ }^{-2} / \Delta t$. Using Equation (2) we can calculate $\Delta t$, which is the time needed by the hydroxyl groups to diffuse from the liquid meniscus to replenish the solution volume within the thin electrolyte layer. $\Delta t$ is found to be about $12 \times 10^{3} \mathrm{~s}(\sim 3.3 \mathrm{~h})$. This limitation in the ionic diffusion rate is confirmed by a recent study of Shavorskiy et al., where the authors observe a significant $I R$ drop in the liquid film at the hematite/liquid electrolyte interface under PEC conditions (for applied potentials above $\sim 1.2 \mathrm{~V}$ vs. RHE) [17]. This mass transport limitation has also an important effect on the achievable current densities within the liquid layer. In a recent study, we masked the bottom of a Pt sample immersed in $\mathrm{KOH}$ 1.0 M aqueous electrolyte and compared to an unmasked electrode [15]. We determined that a bulk (unmasked) current density of about $1.0 \mathrm{~mA} \mathrm{~cm}^{-2}$ under OER conditions corresponds to about $0.3 \mathrm{~mA} \mathrm{~cm}^{-2}$ in the emersed part of the Pt surface [15]. This observation was confirmed by the polarization resistance $\left(\mathrm{R}_{\mathrm{p}}\right)$ for the masked and unmasked configurations, determined using electrochemical impedance spectroscopy (EIS) measurements. In line with the current densities results, the ratio between the two configuration $R_{p}$ (unmasked to masked) was equal to 3.37 [15]. It is important to highlight that it was not possible to completely avoid the contribution arising from the macroscopic liquid meniscus between the sample and the liquid free surface. Therefore, the actual current density at the AP-HAXPES measuring spot might be even lower. As a general remark, the interplay between the applied overpotential and the limitations in the mass transport kinetics through the liquid layer plays a crucial role during "dip and pull" experiments, and needs to be evaluated case by case (depending on the nature of the solid surface, the catalytic activity of the (photo)electrocatalyst etc.). Moreover, the electrode potential at the measuring spot must be corrected for the actual $\mathrm{pH}$ value (since an eventual concentration gradient leads to a $\mathrm{pH}$ gradient as well within the liquid layer). This can be performed by calculating the electrolyte/water ratio using the corresponding photoionization core levels (such as $\mathrm{K} 2 \mathrm{p}$ and $\mathrm{O} 1 \mathrm{~s}$ for a $\mathrm{KOH}$ aqueous solution, as reported in reference [15]).

The lowering of the reaction kinetics within the liquid layer due to the mass transport limitations can be exploited to investigate the evolution of the interfacial properties on a time scale accessible by AP-HAXPES (seconds). For instance, in a recent work we were able to monitor the light-induced formation of a bismuth phosphate $\left(\mathrm{BiPO}_{4}\right)$ layer atop a polycrystalline bismuth vanadate $\left(\mathrm{BiVO}_{4}\right)$ surface, working at the half-cell open circuit potential and in a phosphate-containing electrolyte layer 
with a thickness ranging between 24 and $32 \mathrm{~nm}$ [41]. We found that the $\mathrm{BiPO}_{4}$ formation was reversible upon restoring dark conditions. The $\mathrm{BiPO}_{4}$ formation and dissolution kinetics have been characterized by fitting the temporal trend of the phosphate/water liquid phase (LPW) intensity ratio under visible light and dark conditions, respectively (the spectral components have been determined from the $\mathrm{O} 1 \mathrm{~s}$ core level spectra acquired under light and dark conditions as a function of time). The retrieved time constants of the $\mathrm{BiPO}_{4}$ formation and dissolution were found to be equal to $321 \pm 61 \mathrm{~s}$ and $498 \pm 89 \mathrm{~s}$, respectively [41].

Finally, a general challenge closely related to the use of the aforementioned methods concerns the enhancement of the photoelectron signal coming from the narrow interfacial region atop the solid and buried by the liquid side of the junction. In the next section, using a model solid/liquid junction and numerical simulations, we will address this point and assess the optimal X-ray energy that allows the enhancement of the interface photoelectron signal.

\subsection{Optimization of the AP-HAXPES Experimental Conditions}

The simulations have been generated using the SESSA software [22] (see "Materials and Methods" section for the simulation details). Our model system is constituted by a $\mathrm{TiO}_{2}$ surface functionalized with 1 MLE of APTES, characterized by a thickness of $12.7 \AA$. To complete our model of the solid/liquid interface, a water layer with a thickness of $20 \mathrm{~nm}$ was placed atop the sample surface, as schematically reported in Figure 1. This value has been taken as a realistic representation of the liquid layer thickness typically obtained during "dip and pull" experiments and accessible by HAXPES [11-17].

The use of HAXPES in combination with AP experiments leads to several advantages:

1. The high photon energy (and correspondingly the photoelectron KE) drastically decreases the secondary electron emission cross sections. This has a beneficial effect in limiting the radiation-induced damage suffered by the sample and the correlated radiolysis of water [42];

2. The inelastic scattering between photoelectrons and gas molecules decreases as a result of the large energy difference existing between the X-ray energy and the rotovibrational/electronic excitations and ionization thresholds in the gas molecules (typically falling within the UV-VIS and soft X-ray regions, respectively, for most gases of interest such as $\mathrm{O}_{2}, \mathrm{~N}_{2}, \mathrm{H}_{2} \mathrm{O}, \mathrm{CO}, \mathrm{CO}_{2}$, gaseous hydrocarbons and alcohols);

3. The elastic scattering between photoelectrons and gas molecules, which is responsible for smearing out the photoelectron angular distribution, is less pronounced due to the generally increasing forward focusing effect as the excitation energy increases [43];

4. To maximize the overall photoelectron yield in HAXPES, quasi-normal emission detection is typically coupled with X-ray grazing incidence $\left(\alpha \leq 5^{\circ}\right)$ [44-47]. This has the advantage of minimizing the secondary (inelastic) electron background [46];

5. The high photoelectron KEs lead to increased photoelectron IMFPs in the liquid and thus enable the investigation of solid/liquid junctions through liquid layers whose thickness is of the same order of the photoelectron information depth.

On the other hand, the large probing depth reduces the relative contribution of the interface region with respect to the overall detection (which includes the bulk liquid and solid signals). In addition, the total photoionization cross sections (TPCSs) decrease with increasing photon energy, thereby further reducing the signal coming from the interface (within our model, the signal coming from the APTES overlayer whose thickness is comparable to typical electrical double layer thickness in solution). Figure $4 \mathrm{a}, \mathrm{b}$ clearly illustrate the scenario, reporting the photoelectron IMFP (right axes) and TPCS (left axes) for Si 1s and N 1s core levels (from the APTES overlayer) as a function of photon energy. The IMFP is calculated for photoelectrons traveling in pure water. The IMFP $\left(\Lambda_{\mathrm{e}}\right)$ and $\operatorname{TPCS}(\sigma)$ trends have been fitted using the following relations (Equations (3) and (4), respectively):

$$
\Lambda_{\mathrm{e}}=\mathrm{C} \times(\mathrm{h} v)^{p}
$$




$$
\sigma=\sigma_{0} \times \exp \left[-\left\{\left(\mathrm{h} v-\mathrm{h} v_{0}\right) / \tau\right\}\right]
$$

$\mathrm{C}, p, \sigma_{0}$ and $\tau$ are fitting parameters, whereas $\mathrm{h} v$ denotes the photon energy. Note that we have chosen to report the TPCS instead of the differential PCS (DPCS) in order to provide a general discussion about the photon energy dependency of the PCS, since the DPCS strongly depends on the specific experimental geometry and utilized multipole expansion truncation (see "Materials and Methods" section for details). The TPCSs have been determined by interpolation of the TPCS values reported by Yeh and Lindau [48], whereas the electron IMFPs have been computed using the Tanuma-Powell-Penn (TPP-2M) predictive equation [49]. Table 2 reports the determined $p, \tau$ and $\sigma_{0}$ values for both analyzed core levels, which will be used later to rationalize the observed behavior of the $\mathrm{Si}$ and $\mathrm{N} 1 \mathrm{~s}$ core level photoelectron intensity trend as a function of the photon energy.
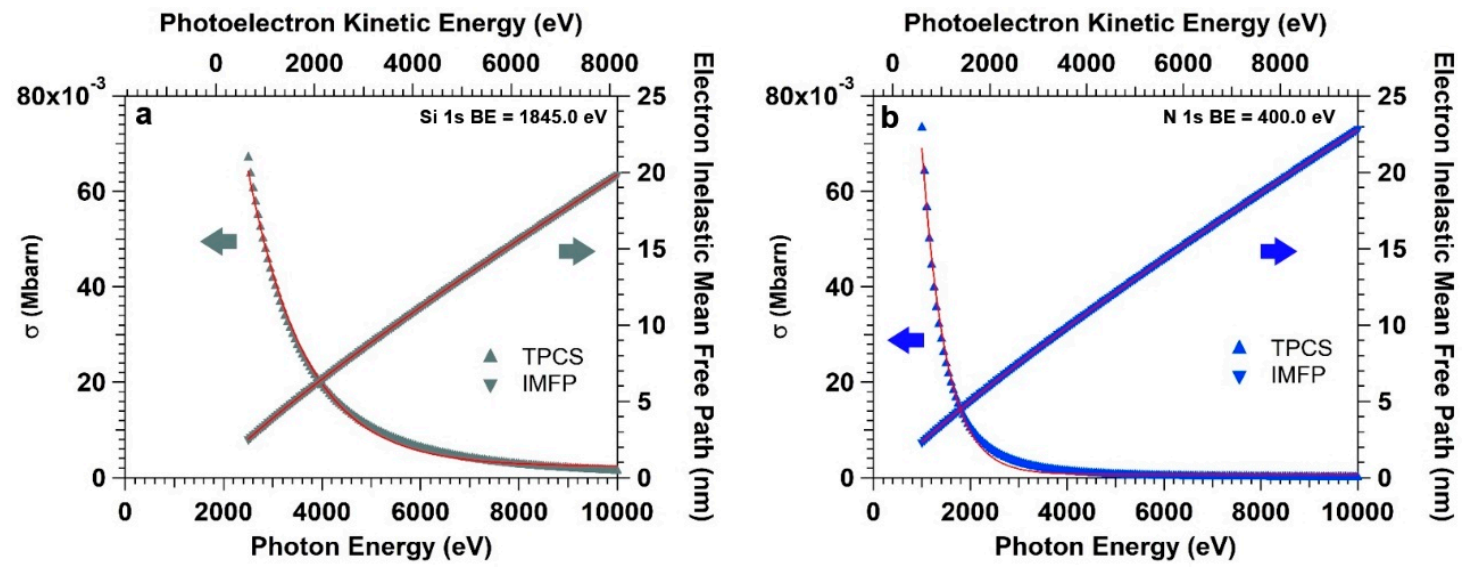

Figure 4. Electron inelastic mean free path (IMFP, right axes) and total photoionization cross section (TPCS, left axes) as a function of the photon energy, for Si 1s (a) and N 1s (b) core levels. The photoelectron kinetic energy scale has been generated from the photon energy values, using Einstein's energy conservation law and a binding energy of $1845.0 \mathrm{eV}$ and $400.0 \mathrm{eV}$ for Si 1s and N $1 \mathrm{~s}$ core levels, respectively. The IMFPs are determined for photoelectrons travelling through water. Red curves are fits according to Equations (3) and (4).

Table 2. $p, \tau$, and $\sigma_{0}$ fitting parameters describing the functional dependency of the electron inelastic mean free path (IMFP) and total photoionization cross section (TPCS) on the photon energy, for Si 1s and $\mathrm{N} 1 \mathrm{~s}$ core levels. Note that the cross section unit is expressed in barn $\left(1 \mathrm{barn}=1 \cdot 10^{-24} \mathrm{~cm}^{-2}\right)$.

\begin{tabular}{cccccc}
\hline Core level & $\begin{array}{c}\text { Nominal Binding } \\
\text { Energy [eV] }\end{array}$ & $\boldsymbol{p}$ & $\boldsymbol{\tau}[\mathbf{e V}]$ & $\mathbf{h} \boldsymbol{v}_{\mathbf{0}}[\mathbf{e V}]$ & $\boldsymbol{\sigma}_{\mathbf{0}}[\mathbf{M b a r n}]$ \\
\hline Si 1s & 1845.0 & $0.843 \pm 0.01$ & $1387 \pm 18$ & 2500 & $0.062($ at $2500 \mathrm{eV})$ \\
N 1s & 400.0 & $0.850 \pm 0.01$ & $622 \pm 7$ & 1000 & $0.071($ at $1000 \mathrm{eV})$ \\
\hline
\end{tabular}

Therefore, it is necessary to find the optimal photon energy that enables to selectively enhance the signal coming from the interfacial region. In addition, as Figure $4 \mathrm{a}, \mathrm{b}$ and Table 2 show, this evaluation needs to be performed for the different core level spectra involved in the investigation, since they are characterized by different cross sections with different photon energy dependency.

Let us start by quantitatively defining the photoelectron intensity for a given core level characterized by principal and angular quantum numbers $n$ and $l$, respectively. The photoelectron intensity $I_{n l}$ in vacuum, normalized by the incident X-ray flux integrated over the irradiated sample volume and the analyzer acceptance solid angle over the surface, is given by Equation (5):

$$
I_{n l}=\int 0^{\infty} \rho(\mathrm{x}, \mathrm{y}, \mathrm{z}) \times(\mathrm{d} \sigma / \mathrm{d} \Omega)_{n l} \times \exp \left[-z /\left(\Lambda_{\mathrm{e}} \times \cos \theta\right)\right] \mathrm{dxdydz}
$$


$\rho(x, y, z)$ is the number of emitters for unit volume (atomic density), $z$ is the photoelectron path in the material measured along the surface normal, $\Lambda_{\mathrm{e}}$ is the IMFP, $(\mathrm{d} \sigma / \mathrm{d} \Omega)_{n l}$ is the DPCS, and $\theta$ is the take-off angle formed between the photoelectron propagation direction and the surface normal. We need now to solve the integral reported in Equation (5) for core levels belonging to the interface (in our case, the APTES overlayer) by systematically changing the photon energy, in order to find the energy value that maximizes $I_{n l}$. This is given by the trade-off between the increase in the probing depth and the DPCS (TPCS) lowering at increasing photon energies. To this end, we have performed a series of SESSA simulations keeping the detection geometry fixed $\left(\alpha=15^{\circ}, \theta=0^{\circ}\right)$ and varying the photon energy of the incoming radiation (considered as $100 \%$ linearly polarized in the orbit (horizontal) plane) with a step of $50 \mathrm{eV}$. Note that the simulated detection geometry is the same to the one experimentally available at BL 9.3.1, ALS. The results of these simulations are reported in Figure $5 \mathrm{a}, \mathrm{b}$ for the Si and N 1s core level photoelectron intensity (left axes), respectively.
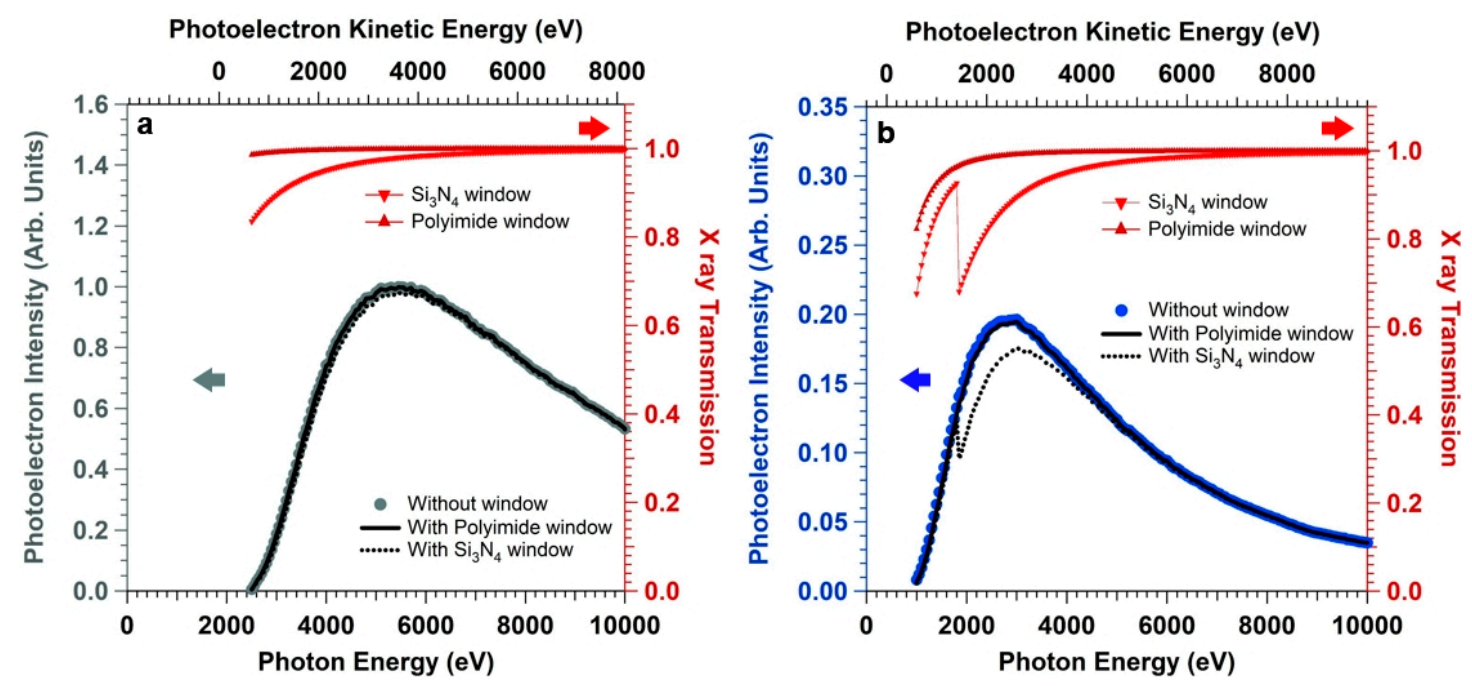

Figure 5. Si 1s (a) and N 1s (b) photoelectron intensity evolution as a function of the photon energy, with and without the X-ray window placed between the X-ray source and the sample. The two elements belong to the APTES overlayer buried by $20 \mathrm{~nm}$ of water. For a better comparison, the reported photoelectron intensities with no simulated absorber are normalized by the maximum value obtained at $5390 \mathrm{eV}$ for the $\mathrm{Si} 1 \mathrm{~s}$ core level. The right axes of Figure $\mathbf{a}, \mathbf{b}$ report the $\mathrm{X}$-ray transmission through a $\mathrm{Si}_{3} \mathrm{~N}_{4}$ and polyimide (Kapton) window. For both materials, the simulated window thickness is $500 \mathrm{~nm}$, which is a common value for X-ray windows used during AP-HAXPES experiments. To simulate the effect of the X-ray window on the photoelectron response, the $X$-ray transmission curves have been convoluted with the photoelectron intensity trends obtained in absence of an X-ray absorber.

The intensity of the $\mathrm{Si} 1 \mathrm{~s}$ core level spectrum $(\mathrm{BE}=1850 \mathrm{eV})$ initially increases for photon energy values between 2500 and $4500 \mathrm{eV}$ (Figure 5a). This is due to the fact that the increasing photoelectron KE leads to an increase of the IMFP, which balances the decay of TPCS (since the photon energy moves away from the Si KLL threshold, centered between 1800 and $1900 \mathrm{eV}$ ). As the photon energy further increases, the exponential decay of the TPCS starts to dominate over the other terms in Equation (5), with the intensity curve leveling off and eventually reaching a maximum at a photon energy of $5390 \mathrm{eV}$ (the intensity curve has been fitted using a lognormal function in order to accurately characterized the maximum). At this energy, the TPCS is about $\mathrm{e}^{-2.0}$ the value at $2500 \mathrm{eV}\left(\sigma_{0}=0.062 \mathrm{Mbarn}\right)$, whereas the probed depth (defined as the depth from which $95 \%$ of the emitted electrons are inelastically scattered, i.e., $3 \cdot \lambda_{\mathrm{e}}$ ) is about $40 \mathrm{~nm}$ (that is two times the thickness of the water layer). For higher energies, the TPCS dominates and a monotone decrease of the photoelectron intensity can be observed in line with the exponential decay of the TPCS. The intensity trend of the $\mathrm{N} 1 \mathrm{~s}$ core level spectrum as a function of the photon energy (Figure 5b) follows a similar qualitative trend, however shifted in 
photon energy (photoelectron KE) due to the lower energy threshold of the KLL transition (at around $400 \mathrm{eV}$ ). The maximum of the intensity curve is reached at a photon energy of about $2850 \mathrm{eV}$, for which the TPCS is equal to about $\mathrm{e}^{-3.0}$ the value at $1000 \mathrm{eV}\left(\sigma_{0}=0.071 \mathrm{Mbarn}\right)$. The information depth at $2890 \mathrm{eV}$ is equal to about $25 \mathrm{~nm}$.

We can therefore rationalize the observed dependencies drawing some general conclusions:

1. For core levels whose electronic excitation energies (and therefore BEs) fall within the soft X-ray region (below $1000 \mathrm{eV}$ ), the TPCS decreases rapidly as the photon energy increases within the hard X-ray region (above $2000 \mathrm{eV}$ ). For core levels characterized by higher electronic excitation energies (approaching or within the hard X-ray region), the corresponding TPCS decreases with a lower rate with the increase of the photon energy;

2. The IMFP follows the same functional dependency with the photon energy for both type of core levels;

3. The combination of the two aforementioned points lead to the following phenomenology: the maximum of the photoelectron intensity of different core levels belonging to the interface region lies at different photon energies. For soft X-ray core levels, the trade-off between relatively high KEs and the fast decay of TPCS leads to probed depths at the curve maximum essentially matching the electrolyte overlayer thickness. For hard X-ray core levels, instead, the slower decay of the TPCS with the photon energy leads to information depth at the maximum of the photoelectron intensity curve higher than the water overlayer thickness. In addition, the intensity curve for hard X-ray core levels is characterized by a broader spectral range compared to that for soft X-ray spectra. In our case, the full-width at half-maximum (FWHM) of the Si 1s intensity curve is about $6500 \mathrm{eV}$, whereas the same for the $\mathrm{N}$ 1s core level is characterized by a FWHM of about $4150 \mathrm{eV}$.

Furthermore, we simulated the effect of introducing an X-ray absorber between the X-ray source and the sample, which is typically done in order to seal the $X$-ray source (beamline or anode source) from the high pressure environment. Figure 5 reports the $X$-ray transmission (right axes) through a $500 \mathrm{~nm}$-thick $\mathrm{Si}_{3} \mathrm{~N}_{4}$ and Kapton window (the calculations of the $X$-ray transmission as a function of the photon energy $(1000 \mathrm{eV}-10000 \mathrm{eV})$ and fixed incidence angle $\alpha$ at the window $\left(\alpha=90^{\circ}\right)$ have been performed using the database of the Center for X-ray Optics (CXRO) of the Lawrence Berkeley National Laboratory (Berkeley, U.S.A) [50]). We can observe that working with hard X-rays (photon energy above $2000 \mathrm{eV}$ ) and Kapton windows keeps the X-ray transmission close to unity even for relatively thick windows (X-ray transmission above $95 \%$ ). On the other hand, for $\mathrm{Si}_{3} \mathrm{~N}_{4}$ windows the Si KLL absorption edge between 1800 and $1900 \mathrm{eV}$ decreases the transmission above $2000 \mathrm{eV}$ (by about $30 \%, 20 \%$, and $10 \%$ at a photon energy of 2000, 2500, and $3100 \mathrm{eV}$, respectively). The $\mathrm{Si}$ and $\mathrm{N}$ 1s photoelectron intensities have been then convoluted with the simulated X-ray transmission. We can observe that the $\mathrm{Si} 1 \mathrm{~s}$ intensity trend (Figure 5a) is basically not influenced by the presence of the window (either $\mathrm{Si}_{3} \mathrm{~N}_{4}$ or Kapton), with an intensity decrease at the maximum (hv $=5390 \mathrm{eV}$ ) of about $2 \%$ in the case of a $\mathrm{Si}_{3} \mathrm{~N}_{4}$ absorber. On the other hand, for the soft X-ray $\mathrm{N}$ 1s core level (Figure $5 \mathrm{~b}$ ), the presence of the $\mathrm{Si}_{3} \mathrm{~N}_{4}$ window leads to an appreciable loss of the photoelectron intensity at the curve maximum (by about $15 \%$ compared to the simulation performed without absorber). Moreover, the maximum of the intensity curve is blue-shifted $(\sim 250 \mathrm{eV})$ by the presence of the $\mathrm{Si}_{3} \mathrm{~N}_{4}$ window compared to the curve obtained with no absorber. In line with the findings obtained for the Si 1s core level intensity curve, the presence of the $500 \mathrm{~nm}$-thick Kapton window does not induce a shift of the $\mathrm{N} 1$ s core level intensity curve, with a loss of signal at the maximum less than $2 \%$ compared to the calculation performed without absorber. We want to highlight that the presence of a differentially-pumped aperture (pin-hole) instead of an X-ray window will lead to the same results obtained for no X-ray absorber, since the former implies a simple photon energy-constant lowering of the photon flux at the sample. 
Overall, this analysis elucidates the importance of tuning the photon energy for different core levels belonging to the interface region buried by a nanometric-thick electrolyte layer, in order to keep the optimal core level "brightness" and enhance the investigation of the solid/liquid interface. Moreover, it shows that another important parameter to keep in mind for enhancing the photoelectron intensity is the choice of the X-ray window, in particular for soft X-ray core levels.

\subsection{Evolution of the Physical/Chemical Properties of the Solid/Liquid Interface as a Function of the Electrolyte $\mathrm{pH}$}

In this section, we will show a practical example of the potentials offered by coupling the "dip and pull" method with AP-HAXPES. We investigated a sol-gel spin-coated $\mathrm{TiO}_{2}$ surface functionalized with 1 MLE of APTES, using a fixed photon energy of $4000 \mathrm{eV}$. This value is close to the average $(4120 \mathrm{eV})$ of the two energies retrieved above to enhance the signal intensity from Si and N 1s core levels within the APTES overlayer. In addition, the photon flux at the sample at photon energies of $2850 \mathrm{eV}$ and $5390 \mathrm{eV}$ at BL 9.3.1 at the Advanced Light Source was not optimal due to experimental limitations of the beamline optics. We studied the solid/liquid interface formation by investigating the surface in its pristine conditions (high vacuum, $\mathrm{HV}$, about $10^{-6} \mathrm{mbar}$ ) (i), by exposing it to $\sim 70 \% \mathrm{RH}$ at room temperature (hydrated conditions, $\mathrm{HC}$ ) (ii), and finally after dipping the surface in pure water and different aqueous electrolytes (iii), changing the $\mathrm{pH}$ from 7 to 14 (see also Table 1). The dipping was performed in about $70 \% \mathrm{RH}$ environment at room temperature ( $\mathrm{p}_{\text {water }} \sim 21 \mathrm{mbar}$ ).

It is important to note that the experimental BE values measured in this work for light elements such as $\mathrm{O}$ and $\mathrm{N}$ are slightly higher than those reported in the literature for similar systems. This might be due to recoil effects when momentum is transferred from the ejected photoelectron to the emitting atom. Recoil is present in all photoemission processes and its effects are non-negligible for high photoelectron KEs and light elements [51,52]. At a photon energy of $4000 \mathrm{eV}$ the calibration performed on gold using the Au $4 \mathrm{f}_{7 / 2}$ core level signal (KE $3916 \mathrm{eV}$ ) is essentially not influenced by the recoil (the corresponding loss is about $10 \mathrm{meV}$ ). On the other hand, the energy loss for the $\mathrm{O} 1 \mathrm{~s}$ (KE $~ 3470 \mathrm{eV}$ ) core level spectrum is about $120 \mathrm{meV}$.

To monitor the formation of the liquid electrolyte layer on the surface, we acquired the $\mathrm{O} 1$ s core level spectrum at all the aforementioned conditions, as reported in Figure 6a. At pristine conditions, the $\mathrm{O} 1 \mathrm{~s}$ spectrum exhibits an intense peak centered at a $\mathrm{BE}$ of about $530.7 \mathrm{eV}$, attributable to the $\mathrm{TiO}_{2}$ lattice oxygen $\left(\mathrm{O}^{2-}\right)[53,54]$. A minor component can be observed at about $533.1 \mathrm{eV}$, most likely due to molecularly adsorbed water $\left(\mathrm{H}_{2} \mathrm{O}_{\text {ads. }}\right)$ on $\mathrm{Ti}^{4+}$ sites [53] and on the APTES terminal $-\mathrm{NH}_{2}$ groups upon exposure to air [55]. It is in fact suggested by Meroni et al. in a recent work that APTES chemisorption on $\mathrm{TiO}_{2}$ mainly occurs through the formation of one or two $\mathrm{Si}-\mathrm{O}-\mathrm{Ti}$ bonds involving the Si headgroup [56], whereas adsorption via the terminal amino group seems instead considerably more labile. Therefore, the Lewis base-character of the amine group might induce water adsorption at the nitrogen atom through hydrogen bond formation with water molecules.

At $\mathrm{HC}$ and for the dipping experiments in the different aqueous electrolytes, we can observe the presence of two new spectral features in the $\mathrm{O} 1 \mathrm{~s}$ core level spectrum. The first, centered at a $\mathrm{BE}$ between 533.6 and $534.0 \mathrm{eV}$ is attributable to liquid phase water (LPW) due to the formation of the liquid layer, whereas the second peak is associated to the gas phase water (GPW) (in the BE range of 536.3 and $536.6 \mathrm{eV}$ ) [53]. The shift in BE of these two components is typically associated to work function changes at the sample surface [57] due to the different explored conditions.

In addition, passing from the pristine conditions to $\mathrm{HC}$ and for the dipping experiments in the different aqueous electrolytes, it is possible to observe the development of a third feature centered at a BE of about $531.8 \mathrm{eV}$. The origin of such a spectral component, under the particular conditions of the experiment, is not trivial and it can be due to a number of different causes. First, the observed $\mathrm{BE}$ is typical of surface hydroxyl groups generated from the well-known dissociative adsorption of water for pressures above $\sim 10^{-3}$ mbar [53]. Second, oxygen-containing carbon compounds from background contamination can also produce a peak at this BE, particularly after filling the chamber 
with water vapor for several minutes at relatively high pressures. The contamination originates most likely from environmental $\mathrm{CO}_{2}$ and hydrocarbons containing $\mathrm{CO}_{\mathrm{x}}$ groups. This is typically caused by the displacement of molecules from the chamber walls upon exposure to water vapor at or above the mbar pressure range or from molecules contained in the water vapor source itself [53]. Third, the formation of non-volatile carbonates during the preparation of the alkaline electrolytes in ambient conditions $\left(\mathrm{CO}_{2}+2 \mathrm{KOH} \rightarrow \mathrm{K}_{2} \mathrm{CO}_{3}+\mathrm{H}_{2} \mathrm{O}\right)$ can lead to the "deposition" of carbonates on the sample surface during the "dip and pull" procedure. The reported BE for carbonate groups (531.9 eV [58]) is also consistent with our findings. The "deposition" of carbonates at the highest investigated pH might be the main cause of the important intensity increase of the spectral component observed when passing from $\mathrm{pH} 12$ to $\mathrm{pH} 14$.

We want now to focus the reader's attention on the photoelectron intensity evolution of the LPW component during the experiment. Figure $6 \mathrm{~b}, \mathrm{c}$ report the LPW to $\mathrm{O}^{2-}$ ratio and the corresponding water layer thickness estimation, respectively. To do so, SESSA simulations have been performed using the same sample structure reported in Figure 1. By changing the water overlayer thickness, the simulated $\mathrm{LPW} / \mathrm{O}^{2-}$ ratio was adjusted to match the experimentally-determined value for each condition. Passing from the first dipping in pure water to the third in $\mathrm{KOH} 10^{-2} \mathrm{M}(\mathrm{pH} 12)$, the $\mathrm{LPW} / \mathrm{O}^{2-}$ ratio changes from about 0.3 to 0.5 , which corresponds to an electrolyte layer thickness between 3 and $4 \mathrm{~nm}$. Within the experimental uncertainty, these are similar thicknesses found at HC, after exposing the sample to about 21 mbar of water $(\sim 2.5 \mathrm{~nm})$. This means that a thin layer of water condensed on the surface at $\mathrm{HC}(\sim 70 \% \mathrm{RH})$, and that the thickness of the liquid layer did not depend on the successive dipping procedures in pure water $(\mathrm{pH} 7)$ and in $\mathrm{KOH} 10^{-4}$ and $10^{-2} \mathrm{M}$ aqueous solutions ( $\mathrm{pH} 10$ and 12, respectively). Differently, at $\mathrm{pH} 14(\mathrm{KOH} 1.0 \mathrm{M})$ the $\mathrm{LPW} / \mathrm{O}^{2-}$ ratio increases up to $\sim 2.5$ (Figure $6 \mathrm{~b}$ ), which corresponds to an electrolyte layer thickness of about $13 \mathrm{~nm}$ (Figure $6 \mathrm{c}$ ).
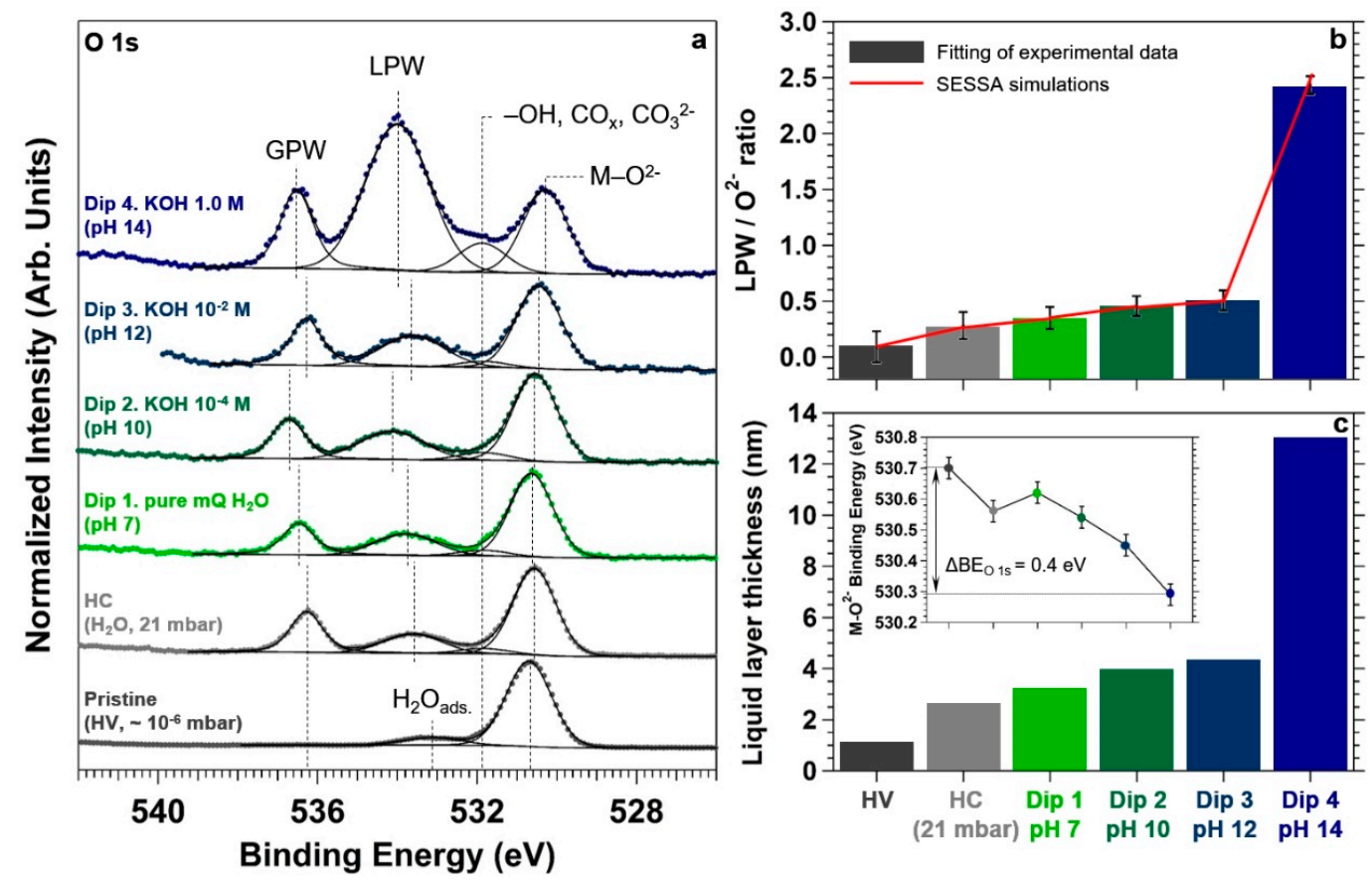

Figure 6. (a) O 1s core level spectra and corresponding multi-peak fitting for the explored experimental conditions (the spectra are normalized by the intensity of the $\mathrm{M}-\mathrm{O}^{2-}$ component); (b): ratio between the liquid phase water (LPW) and the lattice oxygen $\left(\mathrm{O}^{2-}\right)$ component determined via the multi-peak fitting procedure; (c): corresponding estimation of the liquid layer thickness, performed using the intensity attenuation of the $\mathrm{O}^{2-}$ component. The inset reported in Figure c shows the BE negative shift of the $\mathrm{O}^{2-}$ component throughout the experiment, pointing to an upward band bending in $\mathrm{TiO}_{2}$ as consequence of the deprotonation of the surface $-\mathrm{OH}$ groups. The experiment was conducted at room temperature. 
To find the reason for the observed phenomenology, we use the Henderson-Hasselbalch equation to estimate the ratio between the unprotonated $\left(-\mathrm{NH}_{2}\right)$ and protonated $\left(-\mathrm{NH}_{3}{ }^{+}\right)$amine groups as a function of the electrolyte $\mathrm{pH}\left(-\mathrm{NH}_{2} /-\mathrm{NH}_{3}{ }^{+}=10^{\mathrm{pH}-\mathrm{pKa}}\right)$. This procedure allows us to qualitatively assess the net charge at the surface under the different explored conditions, thereby inferring about the interaction between the functionalized charged surface and the liquid water. Using a value of the APTES amine group acid dissociation constant (pKa) of 10.6 as reported by Notsu et al. [59], we find a $-\mathrm{NH}_{2} /-\mathrm{NH}_{3}{ }^{+}$ratio of $2.5 \cdot 10^{-4}, 0.25,25$, and 2500 at $\mathrm{pH} 7,10,12$, and 14 , respectively. This means that for $\mathrm{pH}$ values below (above) the $\mathrm{pKa}$, the amine group is present on the surface mainly in its protonated (unprotonated) form. This is qualitatively demonstrated by the $\mathrm{N} 1 \mathrm{~s}$ core level spectra reported in Figure 7a for the pristine conditions, hydrated conditions and after dipping the sample in the $\mathrm{KOH}$ 1.0 M solution ( $\mathrm{pH} 14)$. The spectrum acquired on the pristine surface exhibits a clear asymmetry toward high BEs, and can be fitted using two spectral components centered at a BE of 400.4 and $401.7 \mathrm{eV}$ (with a FWHM of 1.8 and $2.4 \mathrm{eV}$, respectively). Taking into account a positive $140 \mathrm{meV}$ shift of the BE due to the recoil loss, the identified BEs for these components are in line with previous studies [56] and can be associated with carbamate $(-\mathrm{NHC}(=\mathrm{O}) \mathrm{OH})$ and $-\mathrm{NH}_{3}{ }^{+}$moieties present at the APTES overlayer, respectively. Interestingly, within the detection limit of the technique (about 1 at.\%), we do not observe the presence of unprotonated amine groups (which should generate a peak at a $\mathrm{BE}$ of $399.6 \mathrm{eV}$ [56]). This might be due to the fact that the $-\mathrm{NH}_{2}$ groups readily reacted with environmental $\mathrm{CO}_{2}$ to form carbamates upon exposing the sample to ambient conditions, after the APTES functionalization of the $\mathrm{TiO}_{2}$ surface [60]. Exposing the sample to $\sim 70 \% \mathrm{RH}$ at room temperature leads to an increase of the $-\mathrm{NH}_{3}{ }^{+}$surface concentration (in agreement with the Henderson-Hasselbalch equation for $\mathrm{pH} 7$ ), accompanied by an upward BE shift of both spectral components (by about $0.3 \mathrm{eV}$ ). After dipping the sample in the $\mathrm{KOH} 1.0 \mathrm{M}$ solution ( $\mathrm{pH}$ 14), it is possible to observe the disappearance of the protonated amine component as predicted by the Henderson-Hasselbalch equation. Under these conditions, the $\mathrm{N} 1 \mathrm{~s}$ core level peak could be fitted using only one spectral component, characterized by a FWHM of $2.2 \mathrm{eV}$ and centered at a BE of about $400.0 \mathrm{eV}$. This value is about $0.4 \mathrm{eV}$ lower than the BE reported above for the carbamate moieties present on the pristine surface $(400.4 \mathrm{eV})$. We will give a plausible explanation for such a shift later at the end of this section.

We can then conclude that for $\mathrm{pH}$ values below the $-\mathrm{NH}_{2} \mathrm{pKa}$ (7 and 10), the presence of the protonated amine groups, although positively charged, prevents the formation of a stable and relatively thick water layer leading to the observed partial non-wetting behavior. Above the $-\mathrm{NH}_{2} \mathrm{pKa}(\mathrm{pH} 12$ and 14), no protonated $-\mathrm{NH}_{3}{ }^{+}$groups are essentially present on the surface, while the majority of the free (unprotonated) amine groups are converted into carbamate moieties by the nucleophilic $\mathrm{CO}_{2}$ or $\mathrm{CO}_{3}{ }^{2-}$ attack (keep in mind that the $\mathrm{O} 1$ s revealed an enhanced $\mathrm{CO}_{3}{ }^{2-}$ photoelectron signal at $\mathrm{pH}$ 14 , most likely due to the high availability within the liquid layer of non-volatile carbonates formed during the preparation of the solution). In this case, the absence of formal charges at the surface might weaken its interaction with water. On the other hand, at pH 14 we observe a different behavior, in which the surface shows a higher hydrophilicity character. It is reported that the surface hydroxy groups on $\mathrm{TiO}_{2}$ possess acidic character [61] and can therefore easily donate $\mathrm{H}$ (Brønsted acid) in strong alkaline conditions [61,62]. Therefore, the deprotonation reaction occurring at the solid/liquid interface $\left(-\mathrm{OH}+\mathrm{H}_{2} \mathrm{O} \rightarrow-\mathrm{O}^{-}+\mathrm{H}_{3} \mathrm{O}^{+}\right)$at $\mathrm{pH} 14$ generates a surface negative charge that might be responsible for the stabilization of a thicker liquid layer compared to those observed at lower $\mathrm{pH}$ values.

The development of a negative surface charge driven by the $\mathrm{pH}$ increase leads also to a second effect. In Figure 6a it is possible to qualitatively observe a negative $\mathrm{BE}$ shift of the $\mathrm{O}^{2-}$ component. The inset reported in Figure $6 \mathrm{c}$ shows the $\mathrm{O}^{2-} \mathrm{BE}$ trend as a function of the different explored conditions. The downward BE shift is equal to $0.4 \mathrm{eV}$ passing from pristine conditions to the final dip in $\mathrm{pH} 14$, and it is attributable to an upward band-bending in $\mathrm{TiO}_{2}$ (formation of a depletion layer at the solid/liquid interface). This is confirmed by the observation of the same negative BE shift when acquiring the Ti $2 \mathrm{p}$ core level spectrum, as reported in Figure $7 \mathrm{~b}$ for the same experimental conditions. Passing from pristine to $\mathrm{pH} 14$ conditions, the $\mathrm{BE}$ measured on the Ti $2 \mathrm{p}_{3 / 2}$ spectrum is equal to 459.3 and $458.9 \mathrm{eV}$, 
respectively. The observed negative $0.4 \mathrm{eV}$ shift is thus in agreement with the previous findings. It is worth noting that the photoelectrons generated from the ionization of the $\mathrm{O} 1 \mathrm{~s}$ and Ti 2 $\mathrm{p}_{3 / 2}$ core levels have similar KEs (the difference being about $70 \mathrm{eV}$ ), which leads to the same information depth at a photon energy of $4000 \mathrm{eV}(\sim 17 \mathrm{~nm})$. This means that the information carried by the BE shift is generated by the spectral summation within the depletion layer, convoluted with the exponential decay of the photoelectron intensity. In addition, we want to highlight that no appreciable FWHM change is observed on the lattice oxygen spectral component or in the Ti $2 \mathrm{p}_{3 / 2}$ spectrum, passing from pristine conditions to $\mathrm{pH} 14$. This might be due to the difference between the information depth (using $\mathrm{O} 1 \mathrm{~s}$ and Ti $2 \mathrm{p}_{3 / 2}$ core levels) and the thickness of the space charge region (SCR). Using a concentration of donors of $1 \times 10^{18} \mathrm{~cm}^{-3}$ for intrinsic $n$-doped $\mathrm{TiO}_{2}$ [63] and a band bending potential of $0.4 \mathrm{~V}$ as determined experimentally (assuming flat bands at the pristine conditions), the space charge region thickness can be estimated to be about $45 \mathrm{~nm}$ [64].

We can make use of the adsorption of the APTES molecules at the $\mathrm{TiO}_{2}$ top-most layer to probe the electrical potential value at the upper part of the band-bending potential distribution, by using a core level spectrum from an element belonging to the APTES overlayer (e.g., Si and N 1s). In the case of the $\mathrm{Si}$ 1s spectrum (Figure 7c), the negative BE shift between the pristine and the $\mathrm{pH} 14$ conditions is considerably larger than that observed for $\mathrm{O} 1 \mathrm{~s}$ and $\mathrm{Ti} 2 \mathrm{p}_{3 / 2}$, being equal to $\sim 1.1 \mathrm{eV}$. This value represents therefore the maximum band bending in the depletion layer of $\mathrm{TiO}_{2}$.

On the other hand, as already introduced above, for the $\mathrm{N} 1 \mathrm{~s}$ core level spectrum we observe a negative shift of the carbamate group $\mathrm{BE}$ of about $0.4 \mathrm{eV}$, passing from pristine to $\mathrm{pH} 14$ conditions. This could be generated by two causes. First, the nitrogen atom is not "directly" adsorbed at the $\mathrm{TiO}_{2}$ top-most layer, differently than the silicon atom, but it is screened by three alkyl units from the latter. Therefore, the presence of four single covalent bonds $(\mathrm{Si}-\mathrm{C}, \mathrm{C}-\mathrm{C}, \mathrm{C}-\mathrm{C}$ and $\mathrm{C}-\mathrm{N}$ ) between the silicon and the nitrogen atom might lower the potential experienced in the latter. Second, as schematically reported in Figure $7 \mathrm{~d}$, the nitrogen atom is dangling from the surface into the liquid layer, thereby experiencing the electrical potential drop in solution. The Debye length $\mathrm{k}^{-1}$ for a monovalent ion in an aqueous solution at room temperature is related to the concentration $C$ of the electrolyte by $\mathrm{k}^{-1}=3.04 \times \mathrm{C}^{-1 / 2}\left(\mathrm{C}\right.$ is expressed in $\mathrm{mol} \mathrm{L}^{-1}$, or $\mathrm{M}$, and $\mathrm{k}$ in $\AA$ ). This means that for a $1.0 \mathrm{M}$ solution, the Debye length is equal to about $0.3 \mathrm{~nm}$. Defining the thickness of the Gouy-Chapman diffuse layer as three times the Debye length (i.e., at which distance the potential at the sample surface is $~ 95 \%$ screened in solution), we find that such a thickness is equal to $0.9 \mathrm{~nm}$. We performed a molecular dynamics simulation of the adsorption of one APTES molecule on a rutile $\mathrm{TiO}_{2}(110)$ surface through the formation of one Ti-O-Si bond (Figure 7d). To further confirm this, we used an UFF force field and a convergence cut off of $10^{-6}$. The simulated distance between the nitrogen and the ideal plane containing the-top most layer oxygen atoms is equal to about $0.7 \mathrm{~nm}$, which is similar to the thickness of the diffuse layer calculated above. This means that the nitrogen atom might experience the local potential at the slip plane (that is, at the ideal plane between the diffuse layer and the bulk solution). The two described effects might then account for the different BE shift measured on the $\mathrm{N} 1$ s core level spectra with respect to the value measured using the Si 1s core level. 

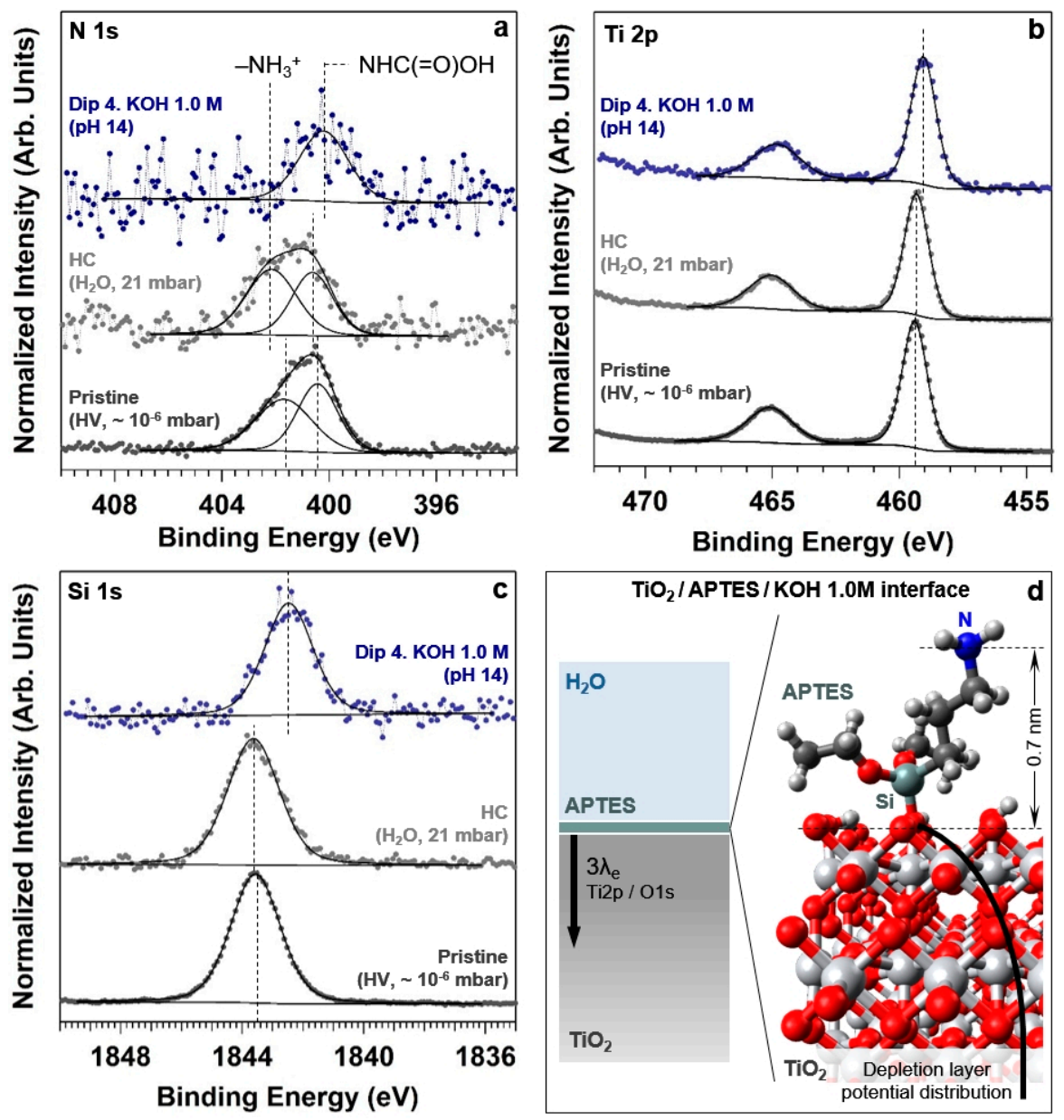

Figure 7. N 1s (a), Ti 2p (b) and Si 1s (c) core level spectra acquired at the pristine conditions, hydrated conditions (HC) and after dipping the sample in the $\mathrm{KOH} 1.0 \mathrm{M}$ solution (pH 14). (d) Relaxed structure obtained from the molecular dynamics simulation of the adsorption of one APTES molecule on a rutile $\mathrm{TiO}_{2}(110)$ surface through the formation of one Ti-O-Si bond (white: titanium; light grey: hydrogen; dark grey: carbon; light green: silicon; red: oxygen; blue: nitrogen).

\section{Conclusions}

In conclusion, we have described the "dip and pull" procedure for the generation of nanometric-thick layers of liquid electrolyte on solid surfaces. The prepared solid/liquid interfaces can be then investigated using AP-XPS. The use of photon energies within the hard X-ray range (above $2000 \mathrm{eV}$ ) allows to probe solid surfaces buried by liquid layers as thick as tens of nanometers, enabling the extension of the parameter space and the possibility to study a wide variety of systems, electrolytes, and electrolyte concentrations.

We discussed the advantages and current drawbacks of using the static "dip and pull" method and related techniques. The main limitation of such techniques is the mass transport in the direction parallel to the interface, which sets restrictions on the current densities achievable in the liquid layer. On the other hand, the lowering of the reaction kinetics within the liquid layer opens up the possibility of performing time-resolved studies on time scales accessible by AP-HAXPES. In addition, this technique is appealing for the investigation of fundamental properties of the solid/liquid interface, such as electrical double layer structure and its modulation by electrical potential and illumination transients, specific ion adsorptions and charge transfers across the interface. This is demonstrated by the recent development of AP-XPS and AP-HAXPES instruments utilizing the "dip and pull" method, at the Advanced Light Source (U.S.A.), Paul Scherrer Institute (Switzerland), MAXIV (Sweden), and BESSY II (Helmholtz-Zentrum Berlin, Germany). 
By using a model system of a solid/liquid organic/inorganic hybrid interface and numerical simulations, we retrieved the optimal photon energy range that enhances the signal coming from the interface when coupling the "dip and pull" method with AP-HAXPES. This is an important parameter that needs to be tuned for each investigated system, due to the fact that the use of hard X-rays to induce photoemission implies relatively low photoelectron intensities due to the low cross sections.

Finally, we presented a practical application of the technique, investigating the APTES-functionalized $\mathrm{TiO}_{2}$ polycrystalline surface in $\mathrm{KOH}$ aqueous electrolytes at different concentrations. Our experiments show that it is possible to monitor in situ the physical/chemical changes of the solid/liquid interface induced by the variation of the electrolyte $\mathrm{pH}$. Our findings open up the possibility to optimize the solid/liquid interface in order to study simultaneously the potential profile in semiconductors (band-bending) and in the liquid side of the junction (double + diffuse layer), using local molecular probes directly functionalizing the semiconductor surface.

We think that the detailed molecular level comprehension of the solid/liquid interface properties will advance materials and process research in many key-technological fields, such as (photo)electrocatalysis, corrosion protection, water remediation, and $\mathrm{CO}_{2}$ capture and conversion.

Author Contributions: Conceptualization, M.F. and D.E.S.; Formal analysis, M.F.; Investigation, M.F., F.F.A. and D.E.S.; Writing—original draft, M.F.; Writing—review \& editing, M.F., F.F.A., E.J.C., Z.L., R.v.d.K. and D.E.S.

Funding: This work was supported by the German Federal Ministry of Education and Research (BMBF project "JointLab-Grundlagen elektrochemischer Phasengrenzen", GEP, \#13XP5023C). This research was partially conducted at the Advanced Light Source of the Lawrence Berkeley National Laboratory, a DOE Office of Science User Facility under contract no. DE-AC02-05CH11231. Z.L. was supported by the National Natural Science Foundation of China (11227902).

Conflicts of Interest: The authors declare no conflict of interest.

\section{References}

1. Salmeron, M.; Schlogl, R. Ambient pressure photoelectron spectroscopy: A new tool for surface science and nanotechnology. Surf. Sci. Rep. 2008, 63, 169-199. [CrossRef]

2. Crumlin, E.J.; Bluhm, H.; Liu, Z. In situ investigation of electrochemical devices using ambient pressure photoelectron spectroscopy. J. Electr. Spectr. Relat. Phenom. 2013, 190, 84-92. [CrossRef]

3. Liu, X.; Yang, W.; Liu, Z. Recent progress on synchrotron-based in-situ soft X-ray spectroscopy for energy materials. Adv. Mater. 2014, 26, 7710-7729. [CrossRef]

4. Crumlin, E.J.; Liu, Z.; Bluhm, H.; Yang, W.; Guo, J.; Hussain, Z. X-ray spectroscopy of energy materials under in situ/operando conditions. J. Elect. Spectr. Relat. Phenom. 2015, 200, 264-273. [CrossRef]

5. Starr, D.E.; Liu, Z.; Hävecker, M.; Knop-Gericke, A.; Bluhm, H. Investigation of solid/vapor interfaces using ambient pressure X-ray photoelectron spectroscopy. Chem. Soc. Rev. 2013, 42, 5833-5857. [CrossRef] [PubMed]

6. Lewerenz, H.-J.; Lichterman, M.F.; Richter, M.H.; Crumlin, E.J.; Hu, S.; Axnanda, S.; Favaro, M.; Drisdell, W.; Hussain, Z.; Brunschwig, B.S.; et al. Operando analyses of solar fuels light absorbers and catalysts. Electrochim. Acta 2016, 211, 711-719. [CrossRef]

7. Roy, K.; Artiglia, L.; van Bokhoven, J.A. Ambient pressure photoelectron spectroscopy: Opportunities in catalysis from solids to liquids and introducing time resolution. Chem. Cat. Chem. 2018, 10, 666-682. [CrossRef]

8. Liu, Z.; Bluhm, H. Liquid/solid interfaces studied by ambient pressure HAXPES. In Hard X-ray Photoelectron Spectroscopy (HAXPES), 1st ed.; Woicik, J., Ed.; Springer: Cham, Switzerland, 2016; pp. 447-466, ISBN 978-3-319-24043-5.

9. Starr, D.E.; Favaro, M.; Abdi, F.F.; Bluhm, D.; Crumlin, E.J.; van de Krol, R. Combined soft and hard X-ray ambient pressure photoelectron spectroscopy studies of semiconductor/electrolyte interfaces. J. Elect. Spectr. Relat. Phenom. 2017, 221, 106-115. [CrossRef]

10. Zaera, F. Surface chemistry at the liquid/solid interface. Surf. Sci. 2011, 605, 1141-1145. [CrossRef] 
11. Axnanda, S.; Crumlin, E.J.; Mao, B.; Rani, S.; Chang, R.; Karlsson, P.G.; Edwards, M.O.M.; Lundqvist, M.; Moberg, R.; Ross, P.N.; et al. Using "tender" X-ray ambient pressure X-ray photoelectron spectroscopy as a direct probe of solid-liquid interface. Sci. Rep. 2015, 5, 9788. [CrossRef]

12. Karslıoğlu, O.; Nemšák, S.; Zegkinoglou, I.; Shavorskiy, A.; Hartl, M.; Salmassi, F.; Gullikson, E.M.; Ng, M.L.; Rameshan, C.; Rude, B.; et al. Aqueous solution/metal interfaces investigated in operando by photoelectron spectroscopy. Faraday Discuss. 2015, 180, 35-53. [CrossRef] [PubMed]

13. Favaro, M.; Jeong, B.; Ross, P.N.; Yano, J.; Hussain, Z.; Liu, Z.; Crumlin, E.J. Unravelling the electrochemical double layer by direct probing of the solid/liquid interface. Nat. Commun. 2016, 7, 12695. [CrossRef] [PubMed]

14. Favaro, M.; Drisdell, W.S.; Marcus, M.A.; Gregoire, J.M.; Crumlin, E.J.; Haber, J.A.; Yano, J. An operando investigation of $(\mathrm{Ni}-\mathrm{Fe}-\mathrm{Co}-\mathrm{Ce}) \mathrm{O}_{\mathrm{x}}$ system as highly efficient electrocatalyst for oxygen evolution reaction. ACS Catal. 2017, 7, 1248-1258. [CrossRef]

15. Favaro, M.; Valero-Vidal, C.; Eichhorn, J.; Toma, F.M.; Ross, P.N.; Yano, J.; Liu, Z.; Crumlin, E.J. Elucidating the alkaline oxygen evolution reaction mechanism on platinum. J. Mater. Chem. A 2017, 5, 11634-11643. [CrossRef]

16. Favaro, M.; Yang, J.; Nappini, S.; Magnano, E.; Toma, F.M.; Crumlin, E.J.; Yano, J.; Sharp, I.D. Understanding the oxygen evolution reaction mechanism on $\mathrm{CoO}_{\mathrm{x}}$ using operando ambient-pressure $\mathrm{X}$-ray photoelectron spectroscopy. J. Am. Chem. Soc. 2017, 139, 8960-8970. [CrossRef] [PubMed]

17. Shavorskiy, A.; Ye, X.; Karslıoğlu, O.; Poletayev, A.D.; Hartl, M.; Zegkinoglou, I.; Trotochaud, L.; Nemšák, S.; Schneider, C.M.; Crumlin, E.J.; et al. Direct mapping of band positions in doped and undoped hematite during photoelectrochemical water splitting. J. Phys. Chem. Lett. 2017, 8, 5579-5586. [CrossRef] [PubMed]

18. Ogletree, D.F.; Bluhm, H.; Hebenstreit, E.D.; Salmeron, M. Photoelectron spectroscopy under ambient pressure and temperature conditions. Nucl. Instrum. Meth. Phys. Res. A 2009, 601, 151-160. [CrossRef]

19. Bluhm, H. Photoelectron spectroscopy of surfaces under humid conditions. J. Elect. Spectr. Relat. Phenom. 2010, 177, 71-84. [CrossRef]

20. Kahk, J.M.; Villar-Garcia, I.J.; Grechy, L.; Bruce, P.J.K.; Vincent, P.E.; Eriksson, S.K.; Rensmo, H.; Hahlin, M.; Åhlund, J.; Edwards, M.O.M.; et al. A study of the pressure profiles near the first pumping aperture in a high pressure photoelectron spectrometer. J. Elect. Spectr. Relat. Phenom. 2015, 205, 57-65. [CrossRef]

21. Fadley, C.S. X-ray photoelectron spectroscopy: From origins to future directions. Nucl. Instrum. Meth. Phys. Res. A 2009, 601, 8-31. [CrossRef]

22. Smekal, W.; Werner, W.S.M.; Powell, C.J. Simulation of electron spectra for surface analysis (SESSA): A novel software tool for quantitative auger-electron spectroscopy and X-ray photoelectron spectroscopy. Surf. Interface Anal. 2005, 37, 1059-1067. [CrossRef]

23. Barlow, S.M.; Raval, R. Complex organic molecules at metal surfaces: Bonding, organisation and chirality. Surf. Sci. Rep. 2003, 50, 201-341. [CrossRef]

24. Abrahams, S.C.; Bernstein, J.L. Rutile: Normal probability plot analysis and accurate measurement of crystal structure. J. Chem. Phys. 1971, 55, 3206. [CrossRef]

25. Cooper, J.W. Multipole corrections to the angular distribution of photoelectrons at low energies. Phys. Rev. A 1990, 42, 6942. [CrossRef] [PubMed]

26. Pascual, J.; Camassel, J.; Mathieu, H. Resolved quadrupolar transition in $\mathrm{TiO}_{2}$. Phys. Rev. Lett. 1977, $39,1490$. [CrossRef]

27. Saravanan, P.; Jayamoorthy, K.; Ananda Kumar, S. Binding interaction and morphology studies of 3-aminopropyltriethoxysilane treated nanoparticles. In Eco-Friendly Nano-Hybrid Materials for Advanced Engineering Applications, 1st ed.; Ananda Kumar, S., Ed.; CRC Press: Boca Raton, FL, USA, 2017; pp. 263-280, ISBN 978-1-77188-295-8.

28. Do Couto, P.C. Electronically Excited Water Aggregates and the Adiabatic Band Gap of Water. J. Chem. Phys. 2007, 126, 014509. [CrossRef] [PubMed]

29. Balej, J. Water vapour partial pressures and water activities in potassium and sodium hydroxide solutions over wide concentration and temperature ranges. Int. J. Hydrogen Energy 1985, 10, 233-243. [CrossRef]

30. Velasco-Vélez, J.J.; Pfeifer, V.; Hävecker, M.; Wang, R.; Centeno, A.; Zurutuza, A.; Algara-Siller, G.; Stotz, E.; Skorupska, K.; Teschner, D.; et al. Atmospheric pressure X-ray photoelectron spectroscopy apparatus: Bridging the pressure gap. Rev. Sci. Instrum. 2016, 87, 053121. [CrossRef] [PubMed] 
31. Velasco-Vélez, J.J.; Pfeifer, V.; Hävecker, M.; Weatherup, R.S.; Arrigo, R.; Chuang, C.-H.; Stotz, E.; Weinberg, G.; Salmeron, M.; Schlögl, R.; et al. Photoelectron spectroscopy at the graphene-liquid interface reveals the electronic structure of an electrodeposited cobalt/graphene electrocatalyst. Angew. Chem. Int. Ed. 2015, 54, 14554-14558. [CrossRef]

32. Bockris, J.; Cahan, B.D. Effect of a finite-contact-angel meniscus on kinetics in porous electrode systems. J. Phys. Chem. 1969, 50, 1307-1324. [CrossRef]

33. Siegbahn, H. Electron spectroscopy for chemical analysis of liquids and solutions. J. Phys. Chem. 1985, 89, 897-909. [CrossRef]

34. Kolb, D.M.; Hansen, W.N. Electroreflectance spectra of emersed metal electrodes. Surf. Sci. 1979, 79, $205-211$. [CrossRef]

35. Hansen, W.N. Electrode resistance and the emersed double layer. Surf. Sci. 1980, 101, 109-122. [CrossRef]

36. Kolb, D.M.; Rath, D.L.; Wille, R.; Hansen, W.N. An ESCA study on the electrochemical double layer of emersed electrodes. Ber. Bunsenges. Phys. Chem. 1983, 87, 1108. [CrossRef]

37. Weingarth, D.; Foelske-Schmitz, A.; Wokaun, A.; Kötz, R. In situ electrochemical XPS study of the $\mathrm{Pt} /[\mathrm{EMIM}]\left[\mathrm{BF}_{4}\right]$ system. Electrochem. Commun. 2011, 13, 619-622. [CrossRef]

38. Booth, S.G.; Tripathi, A.M.; Strashnov, I.; Dryfe, R.A.W.; Walton, A.S. The offset droplet: A new methodology for studying the solid/water interface using X-ray photoelectron spectroscopy. J. Phys. Condens. Matter 2017, 29, 454001. [CrossRef] [PubMed]

39. Stoerzinger, K.A.; Favaro, M.; Ross, P.N.; Hussain, Z.; Liu, Z.; Yano, J.; Crumlin, E.J. Stabilizing the meniscus for operando characterization of platinum during the electrolyte-consuming alkaline oxygen evolution reaction. Top. Catal. 2018, 61, 2152-2160. [CrossRef]

40. Atkins, P.; Paula, J.D. Physical Chemistry, 7th ed.; Oxford University Press: Oxford, UK, 2006; p. 1104, ISBN 9780198700722.

41. Favaro, M.; Abdi, F.F.; Lamers, M.; Crumlin, E.J.; Liu, Z.; van de Krol, R.; Starr, D.E. Light-induced surface reactions at the bismuth vanadate/potassium phosphate interface. J. Phys. Chem. B 2018, 122, 801-809. [CrossRef]

42. Weatherup, R.S.; Wu, C.H.; Escudero, C.; Pérez-Dieste, V.; Salmeron, M.B. Environment-dependent radiation damage in atmospheric pressure X-ray spectroscopy. J. Phys. Chem. B 2018, 122, 737-744. [CrossRef]

43. Fadley, C.S. Hard X-ray photoemission: An overview and future perspective. In Hard X-ray Photoelectron Spectroscopy (HAXPES), 1st ed.; Woicik, J., Ed.; Springer: Cham, Switzerland, 2016; pp. 1-34, ISBN 978-3-319-24043-5.

44. Gorgoi, M.; Svensson, S.; Schäfers, F.; Öhrwall, G.; Mertin, M.; Bressler, P.; Karis, O.; Siegbahn, H.; Sandell, A.; Rensmo, H.; et al. The high kinetic energy photoelectron spectroscopy facility at BESSY: Progress and first results. Nucl. Instrum. Meth. Phys. Res. A 2009, 601, 48-53. [CrossRef]

45. Kobayashi, K. Hard X-ray photoemission spectroscopy. Nucl. Instrum. Meth. Phys. Res. A 2009, 601, $32-47$. [CrossRef]

46. Strocov, V.N. Optimization of the X-ray incidence angle in photoelectron spectrometers. J. Synchrotron Rad. 2013, 20, 517-521. [CrossRef] [PubMed]

47. Rueff, J.-P.; Rault, J.E.; Ablett, J.M.; Utsumi, Y.; Céolin, D. HAXPES for materials science at the GALAXIES beamline. arXiv 2018, arXiv:1807.07522.

48. Yeh, J.-J.; Lindau, I. Atomic Subshell Photoionization Cross Sections and Asymmetry Parameters: $1<Z<103$. Atom. Data Nucl. Data Tables 1985, 32,1-155. [CrossRef]

49. Tanuma, S.; Powell, C.J.; Penn, D.R. Calculation of electron inelastic mean free paths (IMFPs) VII. Reliability of the TPP-2M IMFP predictive equation. Surf. Interface Anal. 2003, 35, 268-275. [CrossRef]

50. Henke, B.L.; Gullikson, E.M.; Davis, J.C. X-ray interactions: Photoabsorption, scattering, transmission, and reflection at $\mathrm{E}=50-30,000 \mathrm{eV}, \mathrm{Z}=1-92$. Atom. Data Nucl. Data Tables 1993, 54, 181-342. [CrossRef]

51. Weiland, C.; Rumaiz, A.K.; Pianetta, P.; Woicik, J.C. Recent applications of hard X-ray photoelectron spectroscopy. J. Vac. Sci. Technol. A 2016, 34, 030801. [CrossRef]

52. Takata, Y.; Kayanuma, Y.; Yabashi, M.; Tamasaku, K.; Nishino, Y.; Miwa, D.; Harada, Y.; Horiba, K.; Shin, S.; Tanaka, S.; et al. Recoil effects of photoelectrons in a solid. Phys. Rev. B Condens. Matter Mater. Phys. 2007, 75, 233404. [CrossRef] 
53. Ketteler, G.; Yamamoto, S.; Bluhm, H.; Andersson, K.; Starr, D.E.; Ogletree, D.F.; Ogasawara, H.; Nilsson, A.; Salmeron, M. The Nature of water nucleation sites on $\mathrm{TiO}_{2}(110)$ surfaces revealed by ambient pressure X-ray photoelectron spectroscopy. J. Phys. Chem. C 2007, 111, 8278-8282. [CrossRef]

54. Head, A.R.; Johansson, N.; Niu, Y.; Snezhkova, O.; Chaudhary, S.; Schnadt, J.; Bluhm, H.; Chen, C.; Avila, J.; Asensio, M.-C. In situ characterization of the deposition of anatase $\mathrm{TiO}_{2}$ on rutile $\mathrm{TiO}_{2}(110)$. J. Vac. Sci. Technol. A 2018, 36, 02D405. [CrossRef]

55. Ukaji, E.; Furusawa, T.; Sato, M.; Suzuki, N. The effect of surface modification with silane coupling agent on suppressing the photo-catalytic activity of fine $\mathrm{TiO}_{2}$ particles as inorganic UV filter. Appl. Surf. Sci. 2007, 254, 563-569. [CrossRef]

56. Meroni, D.; Lo Presti, L.; Di Liberto, G.; Ceotto, M.; Acres, R.G.; Prince, K.C.; Bellani, R.; Soliveri, G.; Ardizzone, $\mathrm{S}$. A close look at the structure of the $\mathrm{TiO}_{2}$-APTES interface in hybrid nanomaterials and its degradation pathway: An experimental and theoretical study. J. Phys. Chem. C 2017, 121, 430-440. [CrossRef] [PubMed]

57. Axnanda, S.; Scheele, M.; Crumlin, E.J.; Mao, B.; Chang, R.; Rani, S.; Faiz, M.; Wang, S.; Alivisatos, A.P.; $\mathrm{Liu}, \mathrm{Z}$. Direct work function measurement by gas phase photoelectron spectroscopy and its application on PbS nanoparticles. Nano Lett. 2013, 13, 6176-6182. [CrossRef] [PubMed]

58. Deng, X.; Verdaguer, A.; Herranz, T.; Weis, C.; Bluhm, H.; Salmeron, M. Surface chemistry of Cu in the presence of $\mathrm{CO}_{2}$ and $\mathrm{H}_{2} \mathrm{O}$. Langmuir 2008, 24, 9474-9478. [CrossRef] [PubMed]

59. Notsu, H.; Fukazawa, T.; Tatsuma, T.; Tryk, D.A.; Fujishima, A. Hydroxyl groups on boron-doped diamond electrodes and their modification with a silane coupling agent. Electrochem. Solid-State Lett. 2001, 4, H1-H3. [CrossRef]

60. Muüller, K.; Lu, D.; Senanayake, S.D.; Starr, D.E. Monoethanolamine adsorption on $\mathrm{TiO}_{2}(110)$ : Bonding, structure, and implications for use as a model solid-supported $\mathrm{CO}_{2}$ capture material. J. Phys. Chem. C 2014, 118, 1576-1586. [CrossRef]

61. Ohtani, B.; Okugawa, Y.; Nishimoto, S.I.; Kagiya, T. Photocatalytic activity of $\mathrm{TiO}_{2}$ powders suspended in aqueous silver nitrate solution. Correlation with $\mathrm{pH}$-dependent surface structures. J. Phys. Chem. 1987, 91 , 3550-3555. [CrossRef]

62. Sham, T.K.; Lazarus, M.S. X-ray photoelectron spectroscopy (XPS) studies of clean and hydrated $\mathrm{TiO}_{2}$ (rutile) surfaces. Chem. Phys. Lett. 1979, 68, 426-432. [CrossRef]

63. Mattioli, G.; Alippi, P.; Filippone, F.; Caminiti, R.; Bonapasta, A.A. Deep versus shallow behavior of intrinsic defects in rutile and anatase $\mathrm{TiO}_{2}$ polymorphs. J. Phys. Chem. C 2010, 114, 21694-21704. [CrossRef]

64. Van de Krol, R. Principles of Photoelectrochemical Cells. In Photoelectrochemical Hydrogen Production, 1st ed.; Van de Krol, R., Grätzel, M., Eds.; Springer: New York, NY, USA, 2012; pp. 13-68, ISBN 978-1-4614-1379-0. 